\title{
Valores Organizacionais e Valores do Trabalho: um estudo com operadores de call center
}

\author{
Kely CÉSAR Martins de Paiva \\ Universidade Federal de Minas Gerais / Faculdade de Ciências EConômicas, Departamento de CiênCIAS AdMinistrativas, CEnTRo \\ De Pós-graduação e Pesquisa em AdMinistração, Belo Horizonte - MG, Brasil
}

\author{
Michelle Regina Santana Dutra \\ Centro Universitário de Belo Horizonte / InStituto de CIÊnCIAS SociaIs Aplicadas, Belo Horizonte - MG, Brasil
}

\begin{abstract}
Resumo
Este estudo analisa como estão configurados os valores organizacionais e os valores do trabalho de operadores de um call center, situado em Belo Horizonte (MG). A análise em tal ambiente laboral, permeado por idiossincrasias, foi realizada por meio de pesquisa de campo, descritiva, com abordagens quantitativa e qualitativa, caracterizando uma triangulação metodológica. Os dados de 399 questionários foram tratados estatisticamente e os oriundos de 22 entrevistas foram submetidos à técnica de análise de conteúdo. Quanto aos valores organizacionais, percebeu-se uma predominância do valor "conformidade", fato compreensível porque tal tipo de organização ser reconhecida pelo respeito às regras, posturas e modelos de comportamentos predefinidos. Em relação aos valores do trabalho, destacam-se os resultados relacionados a "estabilidade" e a "realização no trabalho", pois são valores envolvidos na busca por segurança, adquirida por meio do trabalho, e por prazer e realização pessoal e profissional, respectivamente. O estudo tratou de dois construtos que ainda não haviam sido pesquisados conjuntamente e também contribuiu para a compreensão de particularidades do tipo de empresa abordada. Além disso, a triangulação possibilitou observar disparidades entre dados coletados por meio das técnicas diferenciadas, o que incita a continuidade e a expansão da pesquisa, tanto no que tange aos temas focalizados como aos contextos a ser investigados.
\end{abstract}

Palavras-chave: Valores Organizacionais. Valores do Trabalho. Call Center.

\section{Organizational Values and Work Values: a study with call center operators}

\begin{abstract}
This study analyzes how organizational values and work values are shaped among operators in a call center, located in Belo Horizonte, Minas Gerais, Brazil. The analysis in such a workplace, permeated by idiosyncrasies, was conducted by means of field research, descriptive, through quantitative and qualitative approaches, characterizing a methodological triangulation. Data from 399 questionnaires were addressed statistically and those from 22 interviews underwent the content analysis technique. As for the organizational values, a predominance of the value "compliance" was noticed, a fact that may be understood because this type of organization is recognized for observing predefined behavioral rules, attitudes, and models. Regarding work values, the results related to "stability" and "working achievement" stand out, since they are values involved in the search for security, acquired through a job, and for pleasure and personal and professional fulfillment, respectively. The study examined two constructs that have not been investigated together before and it also contributed to grasp peculiarities of the type of company addressed. In addition, triangulation allowed us to observe discrepancies between data collected by using differential techniques, something which encourages us to continue and extend the research, both concerning the themes focused and the contexts under analysis.
\end{abstract}

Keywords: Organizational Values. Work Values. Call Center.

\section{Valores organizacionales y valores del trabajo: un estudio con operadores de un centro de llamadas}

\begin{abstract}
Este estudio analiza cómo se configuran los valores organizacionales y los valores del trabajo de los operadores de un call center situado en Belo Horizonte (MG). El análisis en este ambiente laboral, lleno de idiosincrasias, se llevó a cabo a través de una investigación descriptiva de campo, con enfoques cuantitativos y cualitativos, que ofrece una triangulación metodológica. Los datos de 399 cuestionarios se trataron estadísticamente y los provenientes de 22 entrevistas se sometieron a la técnica de análisis de contenido. En cuanto a los valores organizacionales, se percibió un predominio del valor "conformidad", hecho comprensible, ya que este tipo de organización es reconocida por el respeto a las normas, actitudes y modelos de comportamiento predefinidos. Con respecto a los valores del trabajo, se destacan los resultados relacionados con "estabilidad" y "realización en el trabajo", pues son los valores involucrados tanto en la búsqueda de la seguridad-adquirida a través del trabajo- como del placer y la realización personal y profesional. El estudio trató dos constructos que aún no habían sido investigados de forma conjunta y también contribuyó a la comprensión de las particularidades del tipo de compañía abordada. Además, la triangulación posibilitó observar las disparidades entre los datos recogidos a través de diferentes técnicas, lo que favorece la continuidad y expansión de la investigación, tanto en relación a los temas enfocados como a los contextos a investigar.
\end{abstract}

Palabras clave: Valores Organizacionales. Valores del Trabajo. Centro de Llamadas.

Artigo submetido em 29 de julho de 2015 e aceito para publicação em 5 de maio de 2016.

DOI: http://dx.doi.org/10.1590/1679-395153725

Cad. EBAPE.BR, v. 15, nº 1, Artigo 3, Rio de Janeiro, Jan./Mar. 2017. 


\section{INTRODUÇÃO}

Como um dos fenômenos mais interessantes no setor de serviços (VASCONCELLOS, MARX e FIGUEIREDO, 2011), os call centers constituem organizações permeadas por idiossincrasias, sendo caracterizados como um ambiente laboral reconhecido ao término do século XX por receber mão de obra de outros setores (agrícola e industrial) (ANTUNES, 2009), criar novos postos de trabalho, como o dos operadores de telemarketing (FREIRE, 2009) e promover o acesso entre empresas e clientes (SILVA, BORINI E TREVISAN, 2007).

Quanto à referida integração, os call centers visam a promover maior comodidade e agilidade nos relacionamentos entre empresas e clientes, tendo em vista sua nova forma de prestação de serviços e de efetivar seus controles, com utilização de tecnologia avançada. Isso é controverso, pois se, por um lado, esse modo de organizar o trabalho possibilita ganhos para a organização, por outro, pode gerar desqualificação progressiva e perdas nas perspectivas de carreira (LANCMAN e SZNELWAR, 2004). Nesse sentido, o call center é um espaço laboral reconhecido pela diminuta qualificação de seus operadores (PARKER, JOHNSON, COLLINS et al., 2013), pela submissão a um tempo quase ininterrupto de trabalho (ANTUNES, 2009; 2010; 2012) e pelos baixos salários praticados, característicos de sua crescente precarização (MENDES, VIEIRA e MORRONE, 2009). Além disso, também é marcado por relações de trabalho instáveis e temporárias (PAIVA, DUTRA e LUZ, 2013, 2015; CAPPELLI e KELLER, 2013) e com frágil proteção jurídica (MENDES, VIEIRA e MORRONE, 2009).

Esse contexto laboral exige uma atuação de modo flexível, ágil e colaborativo por parte dos operadores, que usualmente promove o enfraquecimento das relações de confiança entre as pessoas, causando impactos nos valores dos indivíduos, nas suas atitudes e nos seus comportamentos efetivos, dentro e fora das empresas (SENNETT, 2007). Assim, os operadores de um call center garantem a execução de uma importante e penosa tarefa para a organização, orientados por valores que guiam seus passos, quer seja de maneira igual, semelhante ou mesmo diferente da preestabelecida como modelo, implicando vantagens ou não para a organização (PAIVA, DUTRA e LUZ, 2013; 2015).

No que diz respeito aos valores, é justamente em função da congruência entre eles que cada indivíduo constrói um mapa mental que exerce significativa influência em seu desempenho no dia a dia, assim como na seleção de pessoas de seu convívio

*Fonte da imagem: Google. Disponível em: < https://www.google.com.br/search?q=call+center\&client=ms\&source=Inms\&tbm=isch\&sa=X\&ved= OahUKEwiX5YLRpYDNAhUFHh4KHcfXCkAQ_AUIBygB\&biw=1280\&bih=699\#tbm=isch\&q=call+center+desenho\&imgrc=jZG01yhqqdS5-M\%3A>Acesso em 06 jan. 2017. 
pessoal (ROKEACH, 1981). De modo geral, o indivíduo tende a se aproximar de pessoas que exibam valores equivalentes ou semelhantes aos seus próprios (ROKEACH, 1981). Na pesquisa de Perez (2009), por exemplo, os trabalhadores abordados afirmaram que, mesmo diante de inúmeras transformações globais, a religião continua atuando fortemente como fonte de sentido e experiência em suas vidas, refletindo seus valores no nível pessoal, corroborando a perspectiva de Vieira e Cardoso (2003), no que tange à construção e reconstrução de valores pessoais e suas relações com outros níveis de análise, como o organizacional.

Apesar da polissemia do termo (VIEIRA e CARDOSO, 2003), os valores organizacionais podem ser compreendidos como crenças comungadas e reforçadas a respeito da própria organização (OLIVEIRA e TAMAYO, 2004); quanto aos valores do trabalho, estes dizem respeito aos "motivos que levam as pessoas a trabalhar" (PORTO e TAMAYO, 2008, p. 295) especificamente em determinadas atividades.

Assim, valores pessoais pautam os valores organizacionais e do trabalho, indicando comportamentos que podem ser funcionais, ou não, no que diz respeito aos objetivos organizacionais. Desse modo, entende-se como relevante explorar as temáticas dos valores organizacionais e valores do trabalho, particularmente dentro de um call center, por se tratar de um espaço complexo de trabalho e que abriga mão de obra peculiar, cujas atitudes e comportamentos geram efeitos significativos notórios em termos de eficiência e eficácia individual, grupal e organizacional (PAIVA, DUTRA e LUZ, 2013; 2015).

Diante do exposto, este estudo partiu da seguinte pergunta norteadora: como estão configurados os valores organizacionais e os valores do trabalho de operadores de um call center, em sua própria percepção? Para respondê-la, três objetivos específicos foram delineados, a saber: (1) descrever como se encontram os valores organizacionais de operadores de um call center, localizado em Belo Horizonte (MG), em sua própria percepção; (2) descrever os valores do trabalho de tais operadores; (3) identificar possíveis correlações entre os valores abordados. Assim, o objetivo geral do estudo foi analisar como estão configurados os valores organizacionais e os valores do trabalho de tais operadores.

Destaca-se que este artigo constitui recorte de uma pesquisa mais ampla, que abordou diversos temas comportamentais, como comprometimento organizacional, estresse ocupacional, síndrome de burnout, qualidade de vida no trabalho, vínculos organizacionais, percepções temporais, justiça organizacional e atitudes retaliatórias. Em função dos interesses acadêmicos e de mercado, tal recorte tem aderência às agendas traçadas por outros pesquisadores, em cujos trabalhos verificam-se recomendações para avanços nos estudos sobre as temáticas e o contexto abordados, ou seja, valores, organizacionais e do trabalho (FERREIRA, FERNANDES e SILVA, 2009; GOUVEIA, MILFON, FISHER et al., 2009; HAUFF e KIRCHNER, 2015; PAIVA, 2012; 2013; PORTO e TAMAYO, 2003; 2008; RALSTON, HOLT, TERPSTRA et al., 1997; OLIVEIRA e TAMAYO, 2004; TAMAYO, 2008; VIEIRA e CARDOSO, 2003), e call center (ANTUNES, 2009; 2010; NOGUEIRA, 2012; PAIVA, DUTRA e LUZ, 2013; 2015; CAPPELLI e KELLER, 2013).

Para tanto, procedeu-se a um aprofundamento teórico sobre valores, valores organizacionais e valores do trabalho e delineou-se a metodologia de pesquisa. Após a coleta e análise dos dados foi possível traçar considerações finais, sendo essa a estrutura do artigo.

\section{REFERENCIAL TEÓRICO}

Segundo Schwartz (1999), os valores podem ser caracterizados como os princípios que regem, direcionam ou guiam a vida dos indivíduos, seja por meio de critérios ou metas que vão além de situações específicas classificadas por ordem de importância. Na busca por compreender quais são os motivos que orientam a ação humana, seja em nível individual ou coletivo, o tema conquistou maior atenção de pesquisadores de diversas áreas do conhecimento, abarcando a sociologia, psicologia e antropologia, desenvolvendo uma abordagem psicossocial diferenciada para a análise dos valores, que visa a explicar a interação existente entre os níveis cultural, grupal e individual (ROS, 2006).

Nesse sentido, todos os valores são importantes para compreender o pensamento e as ações humanas (TAMAYO, 2005). Além disso, possuem caráter integrativo, capaz de decodificar as influências dos fatores sociais, políticos, religiosos ou econômicos e delinear as identidades, os comportamentos e as atitudes de indivíduos ou grupos (ROS, 2006). 
Compreender valores, segundo Mourão, Britto, Porto et al. (2003), consiste em se colocar atento às necessidades básicas dos indivíduos. De acordo com os autores, em 1987, os pesquisadores Shalom H. Schwartz e Wolfgang Bilsky apresentaram uma tipologia universal de valores que foi baseada na literatura sobre as necessidades básicas individuais, as quais, em 1992, foram reformuladas por Shalom H. Schwartz e foram identificadas 56 maneiras de apresentação dos valores, sendo estes classificados em 10 tipos motivacionais.

De acordo com Schwartz (1992), os 10 tipos motivacionais consistem em:

1. Poder, no que tange à busca e à preservação da posição social inserida em um sistema social;

2. Autorrealização, quanto ao sucesso pessoal obtido por meio da demonstração de competência em coerência com as regras sociais;

3. Hedonismo, visando ao prazer e à gratificação própria;

4. Estimulação, no que tange a proporcionar novidades e impulsos de vida;

5. Autodeterminação, na busca por independência de pensamento e ação;

6. Filantropia, na busca por compreensão e proteção do bem-estar coletivo e da natureza;

7. Benevolência, na preocupação com o bem-estar de pessoas próximas;

8. Tradição, que consiste em respeito, compromisso e aceitação dos costumes e ideias de uma cultura ou religião;

9. Conformismo, quanto à restrição de ações e impulsos que podem magoar outros ou violar as expectativas sociais e as normas; e

10. Segurança, quanto à proteção, harmonia e estabilidade da sociedade para com seus relacionamentos e também para consigo.

Segundo o autor, a combinação desses valores tende a formar quatro tipos diferentes de comportamentos, observáveis na Figura 1, sendo eles: abertura a mudança, autotranscendência, autopromoção e conservação.

Figura 1

\section{Estrutura Circular dos Valores}

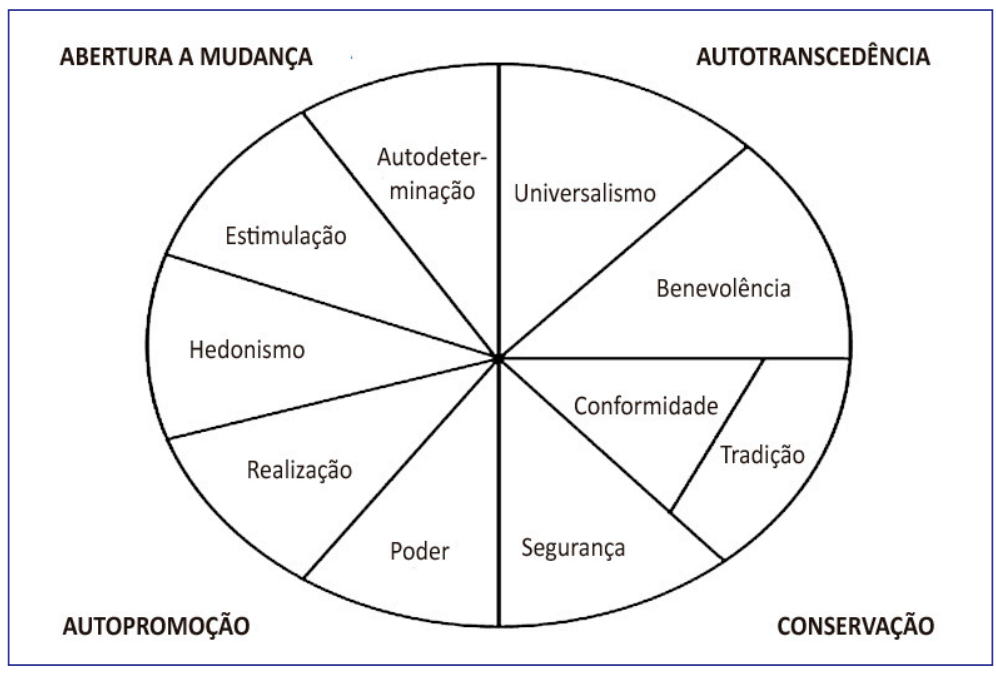

Fonte: Schwartz (2005, p. 31).

Alguns dos estudiosos dessa temática compreendem os valores como antecedentes de comportamentos, como uma base capaz de orientar e guiar a vida dos indivíduos, seja de modo direto, seja de modo indireto, espelhando-se em suas ações (TAMAYO, 2005). Assim, os valores podem ser influenciados pela classe social, pelos valores históricos, sociais e símbolos, assim como pelo convívio social, pela escolaridade, informação recebida e interpretada, além das relações de poder (BORLIDO, 2011). Desse modo, são influenciados por uma série de variáveis sociais, políticas e econômicas (ROS, 2006). 
Desse modo, os valores podem ser associados ao grau de importância atribuído pelo sujeito, podendo sofrer variações de acordo com o julgamento de cada pessoa (SCHWARTZ, 2005). Note-se que os valores individuais são o ponto central da personalidade e a base do autoconceito, internalizado nos momentos de socialização do ser, podendo apresentar-se como crenças, uma vez que os valores guiam o comportamento e conscientizam as pessoas do que deve ou não ser praticado (ROKEACH, 1973). Desse modo, os valores são abarcados de significados e, portanto, as atribuições podem variar de acordo com cada sujeito e com a percepção de mundo de cada um (BORGES, 2005).

Para Andrade (2011), por meio dos valores as pessoas se orientam, guiam seus próprios passos, seja de maneira igual, semeIhante ou diferente da estabelecida como modelo, seja de maneira vantajosa ou não para a organização. Segundo Rokeach (1981), em função da congruência de crenças e valores, percebe-se que cada indivíduo constrói um modelo de mapa mental diante da sua crença, o qual exerce significativa influência em seu comportamento no dia a dia e na seleção de pessoas de seu convívio pessoal, tornando explícito que cada sujeito tende a dar mais valor para os demais na medida em que eles exibem seus valores e que estes sejam equivalentes ou semelhantes aos seus próprios.

Em síntese, as interações sociais, de família, escola e/ou trabalho, são responsáveis por mediar as ações humanas (BORLIDO, 2011) e, no ambiente organizacional, os valores pessoais podem influenciar as tomadas de decisão à medida que os valores organizacionais sejam compatíveis ou semelhantes aos valores dos trabalhadores (MOURÃO, BRITTO, PORTO et al., 2003).

Especificamente sobre os valores organizacionais, estes envolvem princípios ou crenças que são sistematizados hierarquicamente e relacionados às metas e aos comportamentos organizacionais que se identificam como desejáveis. Assim, possibilitam que a realidade organizacional seja reconhecida de modo informal, ou mesmo formal, uma vez que os valores organizacionais estruturam e guiam a vida organizacional no cotidiano, visando a subordinar os interesses individuais aos de ordem coletiva (OLIVEIRA e TAMAYO, 2004; TAMAYO, 2008).

Segundo Schwartz (1992), o estudo dos valores no interior das organizações possibilita identificar quais são as dimensões responsáveis pelos conflitos e convergências nas metas axiológicas da organização e quais delas seus membros devem incorporar visando a atender às expectativas da empresa. Eles podem ser percebidos nos conjuntos de palavras ou frases curtas que carregam em si um forte apelo emocional e que são dirigidas aos indivíduos com o intuito de sua cooptação, mediante o esclarecimento dos comportamentos desejáveis pelos dirigentes (COSTA e CARNEIRO, 2008). Falhando esse processo, ações de incivilidade podem ocorrer e gerar, entre outros resultados deletérios, uma erosão dos valores organizacionais, formalmente definidos ou não (PEARSON e PORATH, 2005).

Assim, os valores organizacionais "formais" são definidos por aqueles que possuem poder no interior da organização (COSTA e CARNEIRO, 2008), mas podem ou não ser comungados pelos demais, o que pode implicar conflitos internos diante da heterogeneidade entre os valores individuais e os desejáveis pela organização (BESHAROV, 2014). A esse respeito, Tamayo, Mendes e Paz (2000) acrescentam que a relação existente entre indivíduo e grupo sempre será conflituosa, uma vez que é difícil conciliar metas e interesses. Maia e Oliveira (2007) lembram que o ser humano é único como espécie e como indivíduo; a este respeito, referenciam Jean-François Chanlat, que destaca sua interface biopsicossocial, ou seja, pertencente à natureza e à cultura que o envolve, com a qual mantém uma relação de influência recíproca.

Para Paiva (2012; 2013), no nível organizacional, os valores derivam e também sustentam não apenas as políticas, mas, substancialmente, as práticas de gestão da organização, as quais, como salientam Gehman, Treviño e Garud (2013), podem não os concretizar de fato no cotidiano de trabalho. Precursor nessa linha de raciocínio, Rokeach (1973) percebe que os valores vão se expressar em vários níveis e situações conforme o cotidiano do indivíduo, o que inclui seu trânsito no meio laboral. Para tanto, ele pode utilizar diversos expedientes, inclusive fingir sua aderência a tais valores (HEWLIN, 2003).

No Brasil, um dos primeiros modelos desenvolvidos referentes à temática resultou na Escala de Valores Organizacionais (EVO), que foi validada por Tamayo e Gondim (1996). O segundo foi o Inventário de Valores Organizacionais (IVO), validado por Tamayo, Mendes e Paz (2000). Por fim, a terceira escala chama-se Inventário de Perfis de Valores Organizacionais (IPVO), que foi validada por Oliveira e Tamayo (2004) e adotada por este estudo, em virtude de ser recente (PAIVA, 2012; 2013).

Esse modelo de Oliveira e Tamayo (2004) pauta-se nos 10 tipos motivacionais de Schwartz (1992), sintetizados em 8 valores organizacionais, cujos conceitos são ilustrados no Quadro 1. 


\section{Quadro 1}

\section{Valores organizacionais}

\begin{tabular}{|l|l|}
\hline Valores organizacionais & Conceitos \\
\hline Realização & Valorização da competência para o alcance do sucesso da organização e dos empregados. \\
\hline Conformidade & $\begin{array}{l}\text { Valorização do respeito às regras e modelos de comportamento no ambiente de trabalho e } \\
\text { no relacionamento com outras organizações. }\end{array}$ \\
\hline Domínio & $\begin{array}{l}\text { Valorização do poder, tendo como meta a obtenção de status, controle sobre pessoas, } \\
\text { recursos e mercado. }\end{array}$ \\
\hline Bem-estar & Valorização da satisfação dos empregados mediante a qualidade de vida no trabalho. \\
\hline Tradição & Valorização dos costumes e práticas consagradas. \\
\hline Prestígio & Valorização do prestígio organizacional na sociedade, mediante a qualidade de produtos. \\
\hline Autonomia & $\begin{array}{l}\text { Valorização de desafios, a busca de aperfeiçoamento constante, a curiosidade, a variedade } \\
\text { de experiências e a definição de objetivos profissionais dos empregados. }\end{array}$ \\
\hline $\begin{array}{l}\text { Preocupação com a } \\
\text { coletividade }\end{array}$ & Valorização do relacionamento com pessoas que são próximas à comunidade. \\
\hline
\end{tabular}

Fonte: Adaptado de Oliveira e Tamayo (2004).

De acordo com Tamayo e Gondim (1996), para conhecer melhor os valores organizacionais, é necessário ater-se às lentes dos trabalhadores, porque eles estão ligados à organização e, portanto, suas respostas resultaram em conclusões mais próximas da realidade organizacional. Afinal, é no dia a dia dos empregados que os valores organizacionais são externalizados, direta e/ou indiretamente, em suas ações, podendo ser considerados "observadores internos, envolvidos ativamente no processo coletivo, para identificar as prioridades axiológicas da organização" (TAMAYO e GONDIM, 1996, p. 66).

Porto e Tamayo (2003) corroboram essa perspectiva acrescentando que há uma relação entre os valores organizacionais e os valores pessoais, uma vez que ambos orientam e direcionam a vida de grupos e indivíduos. Desse modo, os valores das pessoas podem ser compreendidos pelo que elas julgam importante, o que vai pautar sua conduta dentro das organizações onde trabalham e, mais particularmente, no trabalho que realizam (PAIVA, 2012; 2013; LIANG, 2012).

Como destacam Porto e Tamayo (2003), os valores do trabalho também decorrem dos valores pessoais e manifestam-se no ambiente de trabalho. Tais valores representam o que as pessoas estimam e desejam obter por meio de seu trabalho, seus interesses e suas metas pessoais (PORTO e TAMAYO, 2008; LIANG, 2012).

De acordo com Tamayo e Borges (2006), os estudos sobre os valores do trabalho ramificam-se em duas direções, sendo a primeira centrada na investigação do grau de importância que os trabalhadores creditam ao trabalho em relação a outras esferas da vida, tais como família, lazer, religião, sociedade etc. Já a segunda centraliza-se na identificação dos valores atribuídos ao trabalho e à importância relativa que têm entre si.

Para Teixeira (2008), podem ser identificados três valores do trabalho: os pessoais, que pautam condutas adotadas em que se percebem os princípios que guiam a vida organizacional do indivíduo; os sociais, relativos à forma como o indivíduo percebe o outro diante de posições expostas, defendidas e comungadas; e os culturais, nos quais os princípios de um grupo podem ser definidos como valores do trabalho e são compartilhados pelos membros envolvidos ou estabelecidos por líderes ou símbolos organizacionais. Dada sua amplitude, tais valores são espelhados em atitudes espontâneas ou inovadoras que vão além do que se espera para a função que o indivíduo desempenha, delineando seu comportamento na organização (MAIA, OLIVEIRA e XIMENES, 2007; LIANG, 2012). 
Hoch, Andrade e Fossá (2009) ressaltam, em seus achados de pesquisa, que há semelhança entre a Teoria de Valores Individuais, proposta por Schwartz (2005), o modelo de Valores Relativos ao Trabalho, desenvolvido por Ros, Schwartz e Surkiss (1999) e a Escala de Valores Relativos ao Trabalho (EVT), criada por Porto e Tamayo (2003), uma vez que as dimensões dos valores do trabalho correspondem exatamente às dimensões dos valores individuais, como proposto por Schwartz (1992), ou seja, vão espelhar abertura a mudanças, autotranscendência, autopromoção e conservação.

Segundo Porto e Tamayo (2008), ao longo dos anos foram sendo construídos instrumentos de coleta de dados que visam a diagnosticar os valores relativos ao trabalho. Entretanto, os autores constataram que houve falhas na construção desses instrumentos, considerando-se, por exemplo, que, na sociedade contemporânea, o trabalho é o elemento central da identidade social do indivíduo e constitui o meio pelo qual ele busca alcançar suas metas particulares.

Diante dos achados de suas pesquisas, os autores desenvolveram a EVT, que desdobra sua base de análise em quatro valores, realização no trabalho, relações sociais, prestígio e estabilidade, descritos no Quadro 2.

\section{Quadro 2}

\section{Valores do trabalho}

\begin{tabular}{|l|l|}
\hline Valores do trabalho & Conceitos \\
\hline Realização & $\begin{array}{l}\text { Relaciona-se à busca de prazer e realização pessoal e profissional, bem como de independência } \\
\text { de pensamento e ação no trabalho por meio da autonomia intelectual e da criatividade. }\end{array}$ \\
\hline Relações sociais & $\begin{array}{l}\text { Referem-se à busca de relações sociais positivas no trabalho e de contribuições positivas para } \\
\text { a sociedade por meio do trabalho. }\end{array}$ \\
\hline Prestígio & Refere-se à busca de autonomia, sucesso profissional e poder de influência no trabalho. \\
\hline Estabilidade & $\begin{array}{l}\text { Refere-se à busca de segurança e ordem na vida por meio do trabalho, possibilitando suprir } \\
\text { materialmente as necessidades pessoais. }\end{array}$ \\
\hline
\end{tabular}

Fonte: Adaptado de Porto e Tamayo (2003).

Para a realização deste estudo, a EVT foi considerada a mais adequada ao cumprimento dos objetivos, em virtude de ser recente. Além disso, o estudo de Porto, Pilati, Teixeira et al. (2006, p. 1) indica que essa escala "apresenta boa validade e fidedignidade para ser utilizada no desenvolvimento teórico sobre o assunto no Brasil e para realização de diagnósticos em organizações".

Cabe reforçar que os antecedentes do indivíduo, refletidos em seus dados sociodemográficos, junto com o processo de socialização primária, têm impacto direto na composição dos valores pessoais e nas escolhas de suas socializações secundárias, desenvolvidas mediante suas relações com os demais grupos que frequenta (igreja, clube, associação etc.). Os valores pessoais e a socialização secundária têm influência direta e recíproca nos valores que o sujeito compartilha na organização em que atua e também no próprio trabalho que realiza. Tais valores, tanto no nível da organização como no do trabalho, influenciam-se mutuamente, já que o trabalho não se realiza fora de uma estrutura social, baseada em um contexto mais amplo (PAIVA, 2012; 2013).

Nesse sentido, a compreensão dos valores organizacionais e do trabalho assume grande importância, pois têm sido considerados preditores de comportamento no local de trabalho (PORTO e TAMAYO, 2008). Além de motivação individual, os valores também são responsáveis por exercer controle sobre atitudes e comportamentos de terceiros, caracterizando-se, então, sua função social no sentido de conduzir o grupo em que o indivíduo está inserido (SCHWARTZ, 2005).

Em linha semelhante, Borges (2005) sublinha que os valores podem sofrer variações e que isso não é um fato raro ou de se estranhar. Tais variações de valores podem ser identificadas e comparadas de acordo com a nacionalidade, inserção no mercado de trabalho e classe social do sujeito. Assim, as escolhas do sujeito podem dar-se de maneira consciente ou não. A 
manifestação dos valores de cada indivíduo vai variar em relação à gradação que ele the confere, dependendo de sua posição na estrutura social e de suas particularidades, conforme sua história de vida (BERGER e LUCKMANN, 2004), daí a necessidade de esclarecer alguns aspectos relativos ao ambiente laboral onde foi realizada a pesquisa, ou seja, call center.

Os call centers atuais buscam obter eficiência e eficácia nas chamadas e na alocação dos empregados, em especial os operadores, visando a maximizar a produtividade e qualidade de seus atendimentos, selecionando trabalhadores qualificados, que saibam lidar com recursos tecnológicos de suporte com facilidade, além de atender bem às necessidades de cada um dos clientes (COSTA, 2007). Segundo Freire (2009), oportunidade é o que não falta nesse tipo de empresa, diante das constantes mudanças, do ritmo acelerado, passageiro e dinâmico. Trata-se de um ambiente propício a conhecer diversas pessoas, uma vez que dificilmente os operadores sentam-se no mesmo lugar todos os dias e vão ter mais de um supervisor por ano.

De acordo com Laspisa (2007), a maioria dos trabalhadores de um call center é, essencialmente, composta por um conjunto de jovens entre 21 e 30 anos, sem maiores incidências para aqueles em que estão acima dos 40 anos, apesar de alguns autores ressaltarem que um público de empregados mais velhos - acima dos 35 anos - está começando a ocupar lugar. Além disso, é possível notar uma significativa feminilização do mundo do trabalho, especialmente nos setores de prestações de serviço, tal como, por exemplo, o call center, composto por $70 \%$ de mulheres (NOGUEIRA, 2012).

Quanto ao processo de trabalho, Matozo (2000) informa que uma das principais funções de um operador de call center é manter uma relação saudável entre empresa e cliente por meio dos contatos ativos e receptivos (vendas, informações e pesquisas), visando ao fortalecimento da imagem organizacional, da marca e do produto, além de manter um clima organizacional permeado por bons relacionamentos entre colegas, supervisão, coordenação e empresa. Eles devem registrar, sempre que necessário, opiniões, críticas e sugestões dos clientes e também cumprir normas e objetivos determinados pela supervisão em seu posto de trabalho (MATOZO, 2000). Em termos de carreira, esse ambiente de trabalho tem-se caracterizado como uma oportunidade de inserção no mercado de trabalho, um estágio inicial de aquisição de conhecimentos, experiência e maturidade (VASCONCELLOS, MARX e FIGUEIREDO, 2011; PAIVA, DUTRA e LUZ, 2013).

\section{METODOLOGIA}

Com vistas à consecução do objetivo da pesquisa apresentada neste artigo, realizou-se uma pesquisa de campo, descritiva e com abordagens quantitativa e qualitativa (VERGARA, 2009). Assim, foi efetivada uma triangulação entre métodos, visando à complementaridade na compreensão do fenômeno em foco (COLLIS e HUSSEY, 2005). As triangulações podem ocorrer em vários sentidos (dados, pesquisadores, teorias) (COLLIS e HUSSEY, 2005; AZEVEDO, OLIVEIRA, GONZALEZ et al., 2013), porém, a de cunho metodológico é reconhecida por combinar amplitude e profundidade, provendo uma visão e, portanto, uma compreensão mais próxima da complexidade do fenômeno em tela (JICK, 1979; TEIXEIRA, NASCIMENTO e ANTONIALLI, 2013), além de rigor e riqueza na pesquisa (AZEVEDO, OLIVEIRA, GONZALEZ et al., 2013).

A unidade de análise selecionada foi um call center localizado em Belo Horizonte; trata-se de uma organização que atua em 8 estados brasileiros, no mercado há quase 30 anos, prestando serviços especializados para empresas privadas e públicas de grande porte. Além de call center, também atua com cadastro técnico, desenvolvimento de sistemas, limpeza e conservação e terceirização de mão de obra. Devido à exigência de sigilo da empresa, maiores informações a seu respeito não foram permitidas. A unidade de observação foram seus operadores, todos selecionados por acessibilidade (VERGARA, 2009), mediante aprovação (inicial) da gerência e disponibilidade para participar da pesquisa, seja respondendo o questionário e/ou concedendo a entrevista.

Desse modo, a coleta de dados dividiu-se em dois momentos, antecedidos por um primeiro contato com a organização para levantamento do total de trabalhadores, que era de 1.114. No primeiro momento, foi realizado um cálculo amostral, considerando 95\% de confiabilidade e 5\% de margem de erro, a fim de obter a "amostra ideal", cujo resultado foi de 286 questionários preenchidos; o objetivo foi superado, tendo a amostra final 399 questionários válidos para análise. 0 questionário possuía quatro partes, sendo: (1) a primeira focada em dados sociodemográficos, pessoais e profissionais; (2) a segunda composta pelo IPVO, validado por Oliveira e Tamayo (2004), conforme apresentado por Tamayo (2008, p. 329-339), com modificações em sua apresentação, visando a facilitar seu preenchimento, como sugerido por Tamayo (2008) e realizado por Paiva 
(2012; 2013), com escala do tipo Likert, de concordância, variando entre 0 e 5; (3) a terceira contou com a EVT, validada por Porto e Tamayo (2003), como apresentado por Porto e Tamayo (2008, p. 304-305), com uma escala do tipo Likert, de grau de importância, variando de 1 a 5; e (4) um espaço aberto para sugestões, dúvidas ou comentários.

Os dados obtidos por meio desse instrumento foram inseridos, tabulados em planilhas eletrônicas (Microsoft Excel 2007, Minitab 15 e Statistical Package for the Social Sciences 16) e submetidos às análises estatísticas uni e bivariada. Assim, apuraram-se medidas de posição, como médias, percentis (25, 50 - mediana -, e 75) e medida de dispersão, especificamente o desvio padrão; além disso, apuraram-se os percentuais de respondentes por nível de avaliação de cada valor (organizacional e do trabalho) presente nos modelos conceituais adotados. Na parte bivariada, foram realizados testes de correlação linear, especificamente o teste de correlação de Spearman. Esse teste é não paramétrico e foi selecionado porque o resultado do teste Kolmogorov-Smirnov indicou que os dados violaram as condições de normalidade, fato comum em escalas do tipo Likert. Os testes de correlação têm por objetivo mensurar (caso exista) o grau de ligação ou influência exercida por uma variável sobre outra, seja esta de ordem direta ou inversa. O coeficiente utilizado para isso é o rho e pode variar de -1 a 1 , sendo que valores negativos indicam relação de ordem inversamente proporcional e valores positivos de ordem direta. O nível de significância adotado foi de $5 \%$, ou seja, se o resultado do teste indicar valor $p$ abaixo de 0,05 , a correlação é considerada significativa.

No segundo momento de coleta, o apoio da organização foi retirado (unilateralmente), o que dificultou o acesso aos operadores. Uma primeira entrevista foi marcada e, a partir dela, outras pessoas foram indicadas e acessadas para a pesquisa, caracterizando o método snowball (bola de neve); em função disso, as entrevistas foram realizadas nas faculdades onde os entrevistados estudavam ou em restaurantes, lanchonetes ou shopping centers por eles frequentados. 0 roteiro da entrevista foi semiestruturado, de modo a permitir maior verbalização dos entrevistados. Mediante autorização prévia, todas as 22 entrevistas com operadores do call center foram gravadas e finalizou-se essa parte da coleta em função do critério de saturação de dados (GIL, 2009). Note-se que nenhum dos supervisores ou ocupantes de outros cargos gerenciais compareceu às entrevistas previamente agendadas.

Esses dados das entrevistas foram submetidos à análise de conteúdo, nos moldes propostos por Bardin (2009) e operacionalizada conforme orientações de Melo, Paiva, Mageste et al. (2007) e Silva (2006). Para tanto, as entrevistas foram transcritas na íntegra; as respostas foram separadas por pergunta e codificadas para cada entrevistado, variando de E01 a E22 (fase de preparação dos dados); em seguida, foram construídas tabelas sinóticas, que continham todas as respostas dos entrevistados, podendo-se verificar sua recorrência (fase de tabulação quantitativa); e, ao final, todas as entrevistas foram relidas, buscando identificar outros temas e aspectos indicados pelos sujeitos como relevantes, a despeito do próprio roteiro (fase de tabulação temática). Desse modo, as categorias de análise foram escolhidas a priori, espelhando os valores contidos nos modelos teóricos adotados, porém, mantendo abertura para outras possibilidades contidas nos relatos dos entrevistados, como foi o caso das manifestações religiosas que ocorrem com frequência em todas as equipes de trabalho.

Os resultados das análises são dispostos a seguir.

\section{APRESENTAÇÃO E ANÁLISE DOS DADOS}

Em conformidade com os achados de Nogueira (2012), Freire (2009) e Laspisa (2007), a maior parte dos participantes da pesquisa é composta por: mulheres ( $78 \%$ da amostra e $67 \%$ dos entrevistados); jovens com até 25 anos (38,2\% da amostra e 55\% dos entrevistados); solteiros ( $64,8 \%$ da amostra e $77 \%$ dos entrevistados) e com o Ensino Médio completo (65,8\% da amostra e $50 \%$ dos entrevistados). Em ambos os grupos, é notória a presença de pessoas com Ensino Superior (23,9\% da amostra e $45 \%$ dos entrevistados), que não possui necessidades especiais (99,5\% da amostra e $100 \%$ dos entrevistados), de cor de pele parda ( $34 \%$ da amostra e $41 \%$ dos entrevistados), orientação religiosa católica ( $36,8 \%$ da amostra e $59 \%$ dos entrevistados), porém, não praticantes da religião professada ( $44,8 \%$ da amostra e $59 \%$ dos entrevistados) e de orientação sexual heterossexual ( $88,9 \%$ da amostra e $82 \%$ dos entrevistados). No que tange às experiências profissionais, a maioria tem de 2,1 a 5 anos de tempo de trabalho ( $28 \%$ da amostra e $50 \%$ dos entrevistados); de 1 a 2 anos no atual call center ( $19,9 \%$ da amostra e $41 \%$ dos entrevistados) e com remuneração de 1 a 2 salários-mínimos (93,7\% da amostra e 100\% dos entrevistados). 
Considerando que a escala utilizada na pesquisa dos valores organizacionais variava de 0 a 5 (OLIVEIRA e TAMAYO, 2004), notou-se que as médias apuradas se situam, na maioria das vezes, nas faixas superiores de avaliação, porém, próximas ao seu limite inferior $(3,0)$, como se pode observar na Tabela 1, que também exibe outras medidas de posição e dispersão.

\section{Tabela 1}

Estatísticas descritivas dos valores organizacionais, segundo os respondentes

\begin{tabular}{|l|c|c|c|c|c|}
\hline Valores organizacionais & Média & Desvio padrão & $P_{25}$ & Mediana & $P_{75}$ \\
\hline Conformidade & 3,9 & 0,95 & 3,4 & 4,1 & 4,6 \\
\hline Domínio & 3,5 & 1,06 & 3,0 & 3,7 & 4,2 \\
\hline Prestígio & 3,5 & 1,20 & 2,8 & 3,8 & 4,5 \\
\hline Realização & 3,5 & 1,27 & 2,8 & 3,8 & 4,4 \\
\hline Preocupação com a coletividade & 3,3 & 1,30 & 2,4 & 3,6 & 4,3 \\
\hline Autonomia & 3,1 & 1,27 & 2,3 & 3,4 & 4,0 \\
\hline Tradição & 2,9 & 1,06 & 2,4 & 3,0 & 3,7 \\
\hline Bem-estar & 2,4 & 1,43 & 1,2 & 2,5 & 3,5 \\
\hline
\end{tabular}

Fonte: Elaborada pelas autoras.

Destaque-se que o valor "bem-estar" obteve a menor média (2,4, nível mediano), denotando que este parece não ser um valor priorizado no call center, o que reforça o argumento da precarização crescente do trabalho nesse tipo de organização (MENDES, VIEIRA e MORRONE, 2009). No outro extremo, o valor "conformidade" foi o que revelou maior importância na empresa, na opinião dos respondentes (média 3,9, nível elevado), fato esperado mediante as características do trabalho ali executado pelos operadores, ou seja, repetitivo e rotineiro (SILVA, BORINI e TREVISAN, 2007), com baixa exigência de qualificação (PARKER, JOHNSON, COLLINS et al., 2013).Tal análise é reiterada pelos percentuais de pesquisados distribuídos por níveis de avaliação dos valores organizacionais, já que "conformidade" obteve avaliação elevada por parte de $62,3 \%$ dos respondentes e "bem-estar" apresentou o maior percentual de respondentes em nível baixo ( $28,7 \%$ do total), como se visualiza no Gráfico 1.

\section{Gráfico 1}

\section{Percentuais de respondentes, por níveis de avaliação dos valores organizacionais}

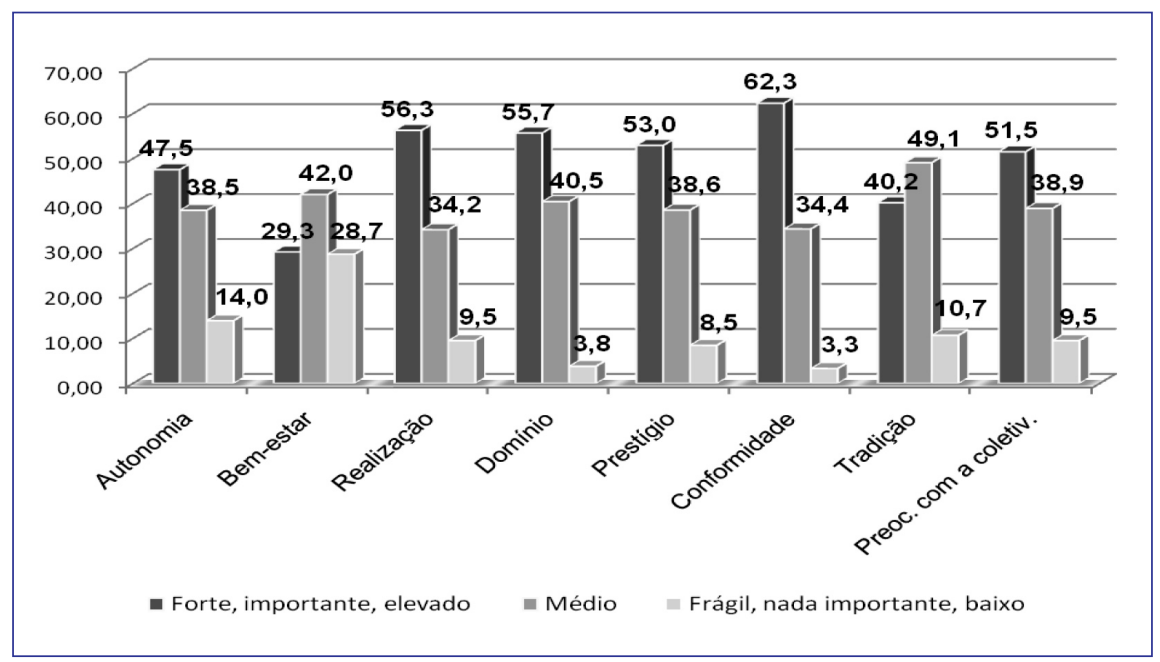

Fonte: Elaborado pelas autoras. 
A valorização da "conformidade" encontra abrigo na literatura que descreve o próprio tipo de trabalho do call center (PARKER, JOHNSON, COLLINS et al., 2013), com elevada cobrança, regras e horários previamente estipulados em busca do cumprimento de elevadas metas (FREIRE, 2009). Nas entrevistas, 16 operadores verbalizaram a necessidade de ir além do que é exigido em termos do cumprimento das regras e das metas, sendo que uma minoria ( 5 entrevistados) indicou não se importar com isso.

Bom, por exemplo, com relação à supervisão sabe... a coordenação ela é bem próxima tanto deles [supervisores] quanto da gente também, fica assim no mesmo ambiente. [...] eu acho que as pessoas fazem, sim [cumprir as regras]! A [call center] olha muito em questão de campanhas, agora mesmo terminou uma que ela vai sortear três motos, três motos... então, [...] as pessoas se empenham, sabe, e eu acho interessante, também, a premiação... ela também é bem chamativa (risos)... Incentiva, motiva sim... Vai ser, é sorteado só para os operadores... É apenas para quem seguiu os requisitos, aí sim será feito o sorteio. (E01)

Esse relato também indica certo nível de alienação nesse ambiente de trabalho (SILVA, OLIVEIRA, CONSTANTINO et al., 2002), marcado por perdas em termos de um domínio de sua própria linguagem, passando a utilizar um vocabulário que as isola de sua identidade social, a fim de estabelecer um vínculo entre o cliente e a empresa, fato que dificulta a aproximação de pessoas com valores semelhantes (ROKEACH, 1981) e mesmo o trabalho colaborativo, podendo promover a fragilização as relações de confiança entre as pessoas (SENNETT, 2007) e chegar até a atos de incivilidade (PEARSON e PORATH, 2005). Além disso, os operadores são, por vezes, privados até do uso do silêncio como forma de escape, uma vez que seu principal ato laboral consiste na fala. Isso é observável em outros relatos, como este:

Talvez a grande maioria... bom, a grande maioria sim... muita gente foge mesmo do que é proposto, mas você é punido quando você foge daquilo, né, tem as advertências, é... um "tempestivo" que eles chamam lá na empresa, que é só um... você não assina nada, mas você é chamado atenção por aquilo e é pontuado em questão de qualidade, entendeu? Aí, naquilo ali, se você sai daquilo ali... por exemplo, se você falar uma frase que não está dentro do padrão de atendimento, você é chamado atenção por isso, porque a [empresa contratante] exige isso junto à [call center]. (E02)

Na percepção dos operadores, a empresa de call center na qual estão inseridos é reconhecida e respeitada no mercado, ou seja, valoriza o "domínio", valor organizacional que atingiu a média de 3,5 e o menor desvio padrão $(1,06)$, ou seja, menor variabilidade de dados na parte quantitativa da pesquisa. Segundo 19 deles, a empresa mostra: ter um diferencial em suas práticas (12 deles) como, por exemplo, prestar serviços, especificamente, para essa empresa contratante (11 deles) e proporcionar e manter um salário diferenciado (4 deles) no ramo de prestações de serviços de telemarketing. Esses podem ser considerados ganhos para a organização, como enunciado por Lancman e Sznelwar (2004).

No entanto, não são todos os indivíduos que conheciam o call center antes de lá trabalhar (3 deles) e, fato mais grave, a maioria se vê como operador direto da empresa contratante, o que constitui um equívoco compreensível, já que o script que pauta suas falas os remete à contratante, certamente imprimindo um caráter integrativo, com impactos em suas identidades, comportamentos e atitudes individuais e coletivas (ROS, 2006).

Além disso, os entrevistados relataram que, anteriormente, o call center tinha um processo de admissão mais rigoroso que foi se perdendo com o tempo e com seu crescimento. Quanto à percepção do respeito e do reconhecimento que a empresa analisada possui no mercado, os seguintes relatos denotam tal decadência:

Era mais respeitada. Era vista assim, das empresas de call centers, ela nem era muito conhecida, eram mais as outras empresas. Agora que ela está assim conhecida [tom de voz pessimista]. E ela já foi muito respeitada porque era difícil até mesmo de entrar na empresa, até mesmo quando eu entrei o processo seletivo foi até muito grande, assim, sabe?! Se a gente for olhar foi bem intenso o processo. [...] O público, para entrar na empresa, era mais selecionado. (E04)

No que tange ao valor "prestígio", média de 3,5 e o segundo menor desvio padrão (1,20), 14 dos entrevistados afirmaram perceber tal diferenciação por sua atuação profissional, tanto por terceiros que acreditam que eles trabalham diretamente 
na empresa contratante (um banco público) como pelo reconhecimento do call center em análise, devido ao salário diferenciado das demais empresas do setor.

Dá, dá [prestígio], sim, porque quando você vem dentro do ônibus com uma pessoa da [nome de outra empresa, call center], uma da [nome de outra empresa, call center] e você da [nome da empresa, call center], você pensa: "aqueles dois colegas ali vão trabalhar que nem eu, vão atender que nem eu, mas eu vou ganhar mais", só isso. Só que muita gente acha que a [nome da empresa, call center] é a melhor empresa de call center... não é, só que ela te dá um pouco de prestígio pelo fato de pagar melhor, entendeu? (E13)

Outros operadores não percebem "prestígio" no âmbito organizacional, informando não ser uma profissão bem vista por terceiros ( 6 deles) e que o prestígio que poderiam receber seria apenas em prol da atuação para a contratante, como informado por 4 entrevistados. Tais posições referem-se, de fato, ao valor do trabalho "prestígio", ou seja, são relacionadas ao que efetivamente o trabalhador faz. Essa conexão entre prestígio no âmbito organizacional e prestígio no escopo do trabalho será mais explorada adiante, na análise das correlações entre os valores estudados, pois foi uma das raras conexões externalizadas pelos entrevistados.

Quanto ao valor organizacional "realização", os dados das entrevistas reforçam o apurado pelos questionários, ou seja: média de 3,5 e a maior variabilidade de dados entre os anteriores discutidos (desvio padrão de 1,27). Essa variabilidade foi observada nas entrevistas deste modo: 3 dos entrevistados se mostraram indecisos quanto a um posicionamento nesse sentido e os demais se distribuíram mais uniformemente entre os que acreditam na importância desse valor dentro da organização e os que acreditam que ele não é comungado nesse nível de análise, o que reforça o argumento do trabalho precarizado, como preconizado por Mendes, Vieira e Morrone (2009).

Eu fui uma excelente profissional durante um período e não fui escolhida para poder me realizar profissionalmente lá dentro [tom de frustração]. (E02)

Proporciona, tanto que eu já tive indicação para fazer processo seletivo lá dentro só que na época eu estava de atestado médico e não fiz, então, assim, eles dão chance para a gente crescer lá dentro, se você quiser se empenhar, você pode realizar, quem tem interesse pode se realizar profissionalmente lá dentro, eles não fecham as portas, não. (E15)

Note-se que os impactos desse valor na vida pessoal do sujeito também foram rememorados, como no seguinte relato:

Sim! Me proporciona realização profissional! Um exemplo que você quer agora? Outro exemplo: a compra da minha televisão, ela é uma televisão que eu há muito tempo queria e comprei devido a estar trabalhando aqui! (E20)

Já o valor organizacional "preocupação com a coletividade" foi percebido por 16 dos entrevistados como importante, salientando sua relação com o cumprimento de metas coletivas (7 deles), a premiações por equipe (4 deles) e em função do resultado (2 deles). Considerando-se que 3 deles manifestaram-se de modo ambíguo (E02, E08, E13), 9 dos entrevistados não percebem tal preocupação no cotidiano da empresa e outros 4 relataram a diferenciação existente entre o tratamento concedido aos que trabalham em áreas diferentes do call center (ativo e receptivo). Os seguintes relatos refletem tais posições:

[...] a gente trabalha em equipe, então, eu acho que sim... então, se um erra, todos pagam por aquilo ali. (E02)

Não, [o call center] não se preocupa. Por exemplo, você tem lá a sua equipe e essa equipe faz um trabaIho bom, ela cumpre as metas direitinho, mas eles sempre, em um período, têm que desfazer a equipe. Então, ao invés deles trabalharem com a produtividade, não, eles gostam de mexer muito até onde já está muito bom. Eles gostam de mudanças. [...]. Um dia está na equipe de um, um dia você está na equipe de outra [...]. (E22) 
Relatos como este refletem, também, o empenho da organização em promover ganhos de produtividade, atuando de maneira flexível e ágil (SENNETT, 2007) no que tange à alocação dos trabalhadores (COSTA, 2007), no caso, os operadores, às custas do enfraquecimento dos laços sociais e de relações de trabalho instáveis e temporárias (PAIVA, DUTRA e LUZ, 2013, 2015; CAPPELLI e KELLER, 2013), sem maiores possibilidades de carreira (VASCONCELLOS, MARX e FIGUEIREDO, 2011; PAIVA, DUTRA e LUZ, 2013; 2015), findando em dificuldades de estabelecer uma colaboração efetiva e enfraquecendo as relações de confiança entre as pessoas (SENNETT, 2007), fomentando, desse modo, relações sociais superficiais no interior da organização, o que é observado na análise do valor do trabalho "relações sociais" e da correlação identificada entre eles.

Por outro lado, a construção de um mapa mental que influencia o desempenho do trabalhador em seu cotidiano laboral, assim como na seleção de pessoas de seu convívio pessoal, pauta-se na aproximação das pessoas que possuam semelhanças axiológicas (ROKEACH, 1981). Nesse sentido, apesar da face laica da organização, o call center promove práticas religiosas com o intuito de "fortalecer" os operadores para o dia de trabalho e o cumprimento de suas metas pessoais e coletivas, como rememorado por parte dos entrevistados e destacado neste relato:

A maioria das equipes, antes de começar a operação, eles fazem uma oração para o dia começar bem, então tem isso, sim... A oração, no caso lá, normalmente uma pessoa puxa e agradece o dia e pede para que todo mundo consiga cumprir seu objetivo e no final dos agradecimentos, dos pedidos, reza um "Pai Nosso", isso na maioria das equipes. Uma oração mais ampla e depois fecha com o "Pai Nosso". Pelo que eu vi lá, praticamente todas [as equipes] têm isso. (E17)

Quanto ao valor "autonomia", percebeu-se que os operadores não têm liberdade para decidir sobre seu trabalho, fato ressaltado pela quase totalidade dos entrevistados (20 deles), sendo que 10 deles expõem que, para a execução de suas atividades, contam com a imposição de um script, mapeando o diálogo esperado para cada tipo de atendimento. Certamente, essa é uma das qualificações observadas por Costa (2007), junto com o saber lidar com recursos tecnológicos, visando a proporcionar um atendimento ágil ao cliente (COSTA, 2007).

Além disso, eles se submetem a elevada cobrança e subserviência a regras (4 deles), retirando do operador o direito de opinar quanto à própria definição e condução de suas atividades (4 deles). Esses dados destoam da parte quantitativa da pesquisa, na qual tal valor obteve média considerada elevada (3,1, ou seja, acima de 3,0). Seus discursos são permeados por comandos definidos previamente, seja pela coordenação do call center, seja pelas exigências formais da empresa contratante. Vários deles caracterizaram o trabalho no call center como robotizado, predominando atividades mecânicas e rotineiras (SILVA, BORINI e TREVISAN, 2007), realidade amplificada mediante a utilização maciça de tecnologia de comunicação que, na verdade, prejudica a interação nos atendimentos e a (multi)concentração dos operadores (SILVA, OLIVEIRA, CONSTANTINO et al., 2002), relacionada a decodificação de letras, números, quadros e enunciados, além do controle da fala e da escrita:

Não. Porque a gente não tem liberdade lá dentro, eu não posso decidir se eu quero ou se eu não quero, eu não posso decidir lá dentro por mim, sempre vai ter alguém que vai decidir por mim em relação ao meu trabalho, a forma de falar, script, então eu não posso fazer da maneira que eu quero, por mais que eu faça certo [...]. (E14)

Além disso, decisões imediatistas complicam sua vida pessoal.

Não, porque muitas das vezes eles acham que a gente tem que viver só para o trabalho e se esquecem que tem uma vida pessoal lá fora, eles ficam decidindo as coisas muito em cima da hora e joga para o operador e você tem que se virar e não é sempre assim [na vida pessoal], porque, afinal, você não vive só para aquele foco, já que você tem uma outra vida também [extratrabalho]. (E09)

No que diz respeito ao valor "tradição", 17 dos entrevistados externalizaram fatos que espelham costumes e práticas organizacionais usuais, dados estes que destoam da parte quantitativa da pesquisa, na qual esse valor obteve a segunda menor média (2,9, nível mediano). Foram mencionadas desde a realização de campanhas com intuito motivacional (6 deles), que incluem cobranças por metas e por qualidade na prestação do serviço, além de momentos de socialização e de incentivo ao desempenho, inclusive por meio de orações religiosas. Por outro lado, 8 dos entrevistados mencionaram o não cumprimento de tais tradições, atribuindo a responsabilidade a falhas na organização da área de recursos humanos (3 deles), ausência de 
benefícios como "vale-refeição" (2 deles) e ginástica laboral ( 2 deles), além de tratamento desigual entre duas áreas do call center, sendo o ativo mais "prestigiado" que o receptivo, tendo em vista os resultados que gera para a empresa. Visando a evitar atos de incivilidade (PEARSON e PORATH, 2005), frisem-se as premiações com o intuito de incentivar os operadores (FREIRE, 2009) a se comportar dentro do esperado, amplamente relatadas pelos entrevistados:

A maioria é funcionários, jovens, né? Então, querendo ou não, eles têm uma forma de trabalho mais liberal, pode-se falar assim, e a maioria dos call center é assim e é o mesmo cronograma. Qualquer call center que você for é a mesma coisa. É aquela coisa, cada um no seu PA, cada um no seu [posto de] atendimento, a cobrança maior é a questão das pausas, qualquer call center que você for eles vão cobrar sempre dos funcionários é isso, pausa e TMA [tempo médio de atendimento], mas a [call center], ela tem uma coisa que é bem maior que é a questão do atendimento. Lá, nós somos monitorados pela [empresa contratante] o tempo todo, então, assim, não tem esse negócio de rispidez, você tem que falar com o cliente, "o senhor", sabe? Aquilo que eles falam com um sorriso na voz, então eu acho que qualquer call center é assim... A única coisa que eu acho que é diferente na [call center] é isso que eles cobram muito a qualidade no atendimento. Eu até mesmo ganhei uma moto em uma campanha aí da [call center], eu ganhei uma moto, eu nunca trabalhei em call center, foi a primeira vez e eu ganhei uma moto. A campanha era: você não podia ter falta ou dar atestado durante dois ou três meses, eu acho, aí, eu ganhei uma moto nessa campanha: no sorteio de três motos, eu ganhei uma. Foi, foi a campanha do final de ano. [...] Lá tem essas coisas de ir fantasiado [...] e sempre tem campanhas... a última campanha que teve, foram vários prêmios também. Sempre tem prêmios, eles dão prêmios, ou, folga... é, acho que na penúltima campanha que teve foi televisão, DVD, bicicleta... teve uma colega minha que ganhou uma bicicleta, eles dão bastante prêmios lá. (E15)

Por fim, "bem-estar" foi o valor organizacional avaliado mais negativamente pelos respondentes do questionário (menor média, 2,4, nível mediano; $28,7 \%$ dos respondentes em nível frágil, baixo), fato que encontrou eco nos dados dos entrevistados, já que 18 deles não percebem investimentos organizacionais em prol do bem-estar dos operadores, indicando que tal valor não é comungado pela maior parte do quadro de operadores. Isso confirma o pressuposto de Besharov (2014) a respeito de que valores podem não ser comungados na organização, nem observáveis em suas práticas de gestão, como mencionaram Gehman, Treviño e Garud (2013), ou seja, o call center parece não concretizar tal valor nas ações cotidianas, mostrando-se desatento às necessidades básicas dos indivíduos, como conceituadas por Schwartz (1992) e Mourão, Britto, Porto et al. (2003).

É igual o que eu te falei, como ela [call center] não visa ao operador e visa só à qualidade de atendimento, então, a gente... ninguém trabalha à vontade, por exemplo, é aquela pressão, né... [...] Você trabalha, assim, muito sobre pressão psicológica, o tempo todo. É o tempo todo você sendo vigiado, é o tempo todo você sendo ouvido [monitoria em tempo real]. (E02)

[...] é ligação demais, é muito problema, muito cliente xingando, é muita coisa, você fica com a cabeça estressada. [...] sinceramente, não acredito que se importe muito com isso não, ar-condicionado no talo. (E10)

Poucos entrevistados mencionaram um estado de espírito positivo promovido pela organização, mas fruto muito mais de sua própria motivação para o trabalho, como sintetiza este relato:

Sim! Me garante, sim, bem-estar, pois eu gosto de trabalhar aqui e me sinto bem! Sempre venho trabalhar feliz, alegre e vou embora feliz e alegre. (E20)

Assim, os valores organizacionais parecem ser observados e comungados pelos operadores, não de forma unânime nem na mesma intensidade.

Considerando-se que a escala utilizada na pesquisa dos valores do trabalho variava de 1 a 5 , notou-se que a maioria das médias apuradas se situa nas faixas superiores de avaliação, como se pode observar na Tabela 2, que também exibe outras medidas de posição e dispersão. 
Tabela 2

Estatísticas descritivas dos valores do trabalho, segundo os respondentes

\begin{tabular}{|l|c|c|c|c|c|}
\hline Valores do trabalho & Média & Desvio padrão & $P_{25}$ & Mediana & $P_{75}$ \\
\hline Estabilidade & 4,3 & 0,78 & 3,9 & 4,4 & 4,7 \\
\hline Realização & 3,9 & 0,72 & 3,5 & 4,0 & 4,4 \\
\hline Relações sociais & 3,8 & 0,71 & 3,3 & 3,8 & 4,3 \\
\hline Prestígio & 3,0 & 0,75 & 2,5 & 3,0 & 3,5 \\
\hline
\end{tabular}

Fonte: Elaborada pelas autoras.

O valor "prestígio" no âmbito do trabalho apresenta um patamar de dados bastante inferior aos demais, ainda que seus escores não se encontrem em uma faixa de avaliação negativa (abaixo de 2,5). Nas entrevistas, tal situação também foi observada, usualmente associando a falta de prestígio ao tipo de trabalho realizado - rotineiro, repetitivo (SILVA, BORINI e TREVISAN, 2007), ininterrupto (ANTUNES, 2009; 2010; 2012), com baixa remuneração e precarizado (MENDES, VIEIRA e MORRONE, 2009) - e suas consequências para a vida do trabalhador - adoecimento físico e mental (ANTUNES, 2009, 2010, 2012), ausência de perspectiva de carreira (VASCONCELLOS, MARX e FIGUEIREDO, 2011; PAIVA, DUTRA e LUZ, 2013; 2015), mediante relatos como o que se segue:

[...] o operador de telemarketing, já é... eu acho que é meio assim, quando você fala: "Ah, eu sou operador de telemarketing", aí a pessoa já fala assim: "Ah!" [tom de desprezo] Entendeu? [...] O operador de telemarketing incomoda as pessoas, entendeu? Pelo menos, assim, no ativo, ele acaba incomodando as pessoas, então, assim, a gente não tem prestígio com relação a isso... Bom, ninguém nunca se sentiu orgulhoso por eu ser operadora de telemarketing não... pelo menos não na minha família... ninguém nunca quis que eu entrasse [no call center], para te falar a verdade, nem meu marido, nem mãe e nem pai... ninguém nunca quis não, sabe, porque é um trabalho estressante, né... (E02)

Em outra perspectiva de análise, o Gráfico 2 possibilita a visualização dos percentuais de respondentes por nível de análise da importância dos valores no trabalho. Note-se a disparidade entre os percentuais relativos ao "prestígio" e os demais valores no trabalho. Pode-se verificar que a "realização no trabalho" é mais bem avaliada pela maioria das pessoas, apesar de ter apresentado a segunda maior média $(3,9)$, abaixo apenas de "estabilidade". 


\section{Gráfico 2}

Percentuais de respondentes, por níveis de avaliação dos valores do trabalho

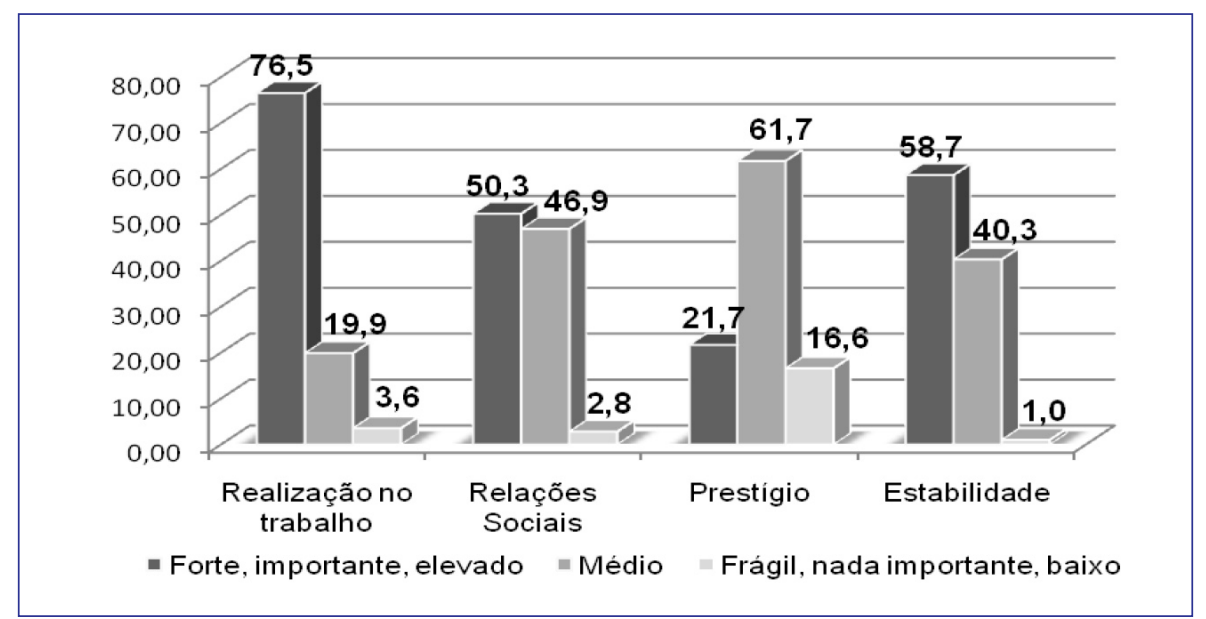

Fonte: Elaborado pelas autoras.

Em relação ao valor do trabalho "estabilidade", foram percebidas posições positivas dos entrevistados voltadas à estabilidade pessoal (12 deles) e financeira (15 deles); no entanto, também foram verbalizadas posições contrárias, associando-se os impactos da instabilidade à saúde dos indivíduos, nos moldes apontados por Antunes $(2009,2010,2012)$ :

Ah... eu num vou falar que não, porque, porque você vê que têm cargos aí, hoje, que são de assistentes administrativos que talvez não estejam ganhando lá, em oito horas, o que a gente ganha em seis horas, e isso, se você for pegar aí, o jornal, você vai ver [...] (E03)

Não, porque... call center a qualquer momento pode mudar! Porque, por ser terceirizada a [call center], então se a [empresa contratante] mandar "Corta 300 vagas!", então, são 300 vagas que eles vão cortar! Hum... Então, não tenho estabilidade, é como se estivéssemos a andar em ovos ali dentro. Ali dentro, realmente, é andar em ovos! (E07)

A financeira te digo que sim, porque eles não mandam embora [...] e, assim, os descontos lá você vai ter só se você faltar, então, a estabilidade financeira tem [...]; a pessoal, a maioria das pessoas sai de lá estressado, ninguém é tranquilo lá dentro, entendeu? A estabilidade pessoal não tem, porque é um serviço estressante, então, você, hoje, pode chegar lá tranquilo, às vezes cai um atendimento que te estressa o resto do dia [...]. (E13)

Especificamente sobre "realização no trabalho", foram observados, por meio das entrevistas, os ganhos em termos do conhecimento adquirido, mediante a oportunidade de inserção no mercado de trabalho (VASCONCELLOS, MARX e FIGUEIREDO, 2011; PAIVA, DUTRA e LUZ, 2013, 2015). Soma-se a isso a interação interpessoal - com o cliente, via ligação - e o contato com uma grande empresa (a contratante), o que estimula o prazer e a realização, tanto pessoal como profissional, mesmo que tal relação ocorra de modo indireto, viabilizada pelo próprio trabalho no call center. No campo pessoal, observe-se:

Sim! Porque é uma experiência a mais que eu posso levar, não só para o ramo de telemarketing, mas para a vida toda... além disso, a gente interage bastante com o cliente, então se aprende novas coisas... como a [call center] [...] trabalha pra [empresa contratante], como ela atua para uma grande empresa, né, então, além de aprender coisas para passar para o cliente, eu também aprendo coisas que servem para a minha própria vida. (E05)

Na esfera profissional, essa inserção no mercado é percebida como um degrau, um trampolim para outras oportunidades (VASCONCELLOS, MARX e FIGUEIREDO, 2011; PAIVA, DUTRA e LUZ, 2013; 2015) e, assim, os posicionamentos quanto à realização foram menos otimistas: 
Não! Como eu havia falado anteriormente é um... é como que se fosse um bico, né, já que é um trabalho que me proporciona... que me ajuda, a conciliar com a minha faculdade, mas, que não é o meu objetivo de trabalho, na verdade... eu tenho outros a serem alcançados. (E09)

Não, não concordo, não, porque, assim... depois que eu tive a primeira experiência com call center não quis mais, estou ali mesmo só porque eu preciso, então, não sou realizada profissionalmente. (E13)

Diante desses dados, o call center parece continuar a ser visto como um emprego transitório (VASCONCELLOS, MARX e FIGUEIREDO, 2011; PAIVA, DUTRA e LUZ, 2013; 2015), que possibilitará ao trabalhador crescer até certo ponto e, em seguida, deslocar-se para outras organizações.

No momento, sim, não só na questão financeira, mas em questão do ambiente de trabalho é um ambiente bom, [...] mas não quer dizer que eu quero ficar ali para sempre, mas, no momento, o que eu quero para mim é aquilo ali. (E15)

Quanto às "relações sociais", note-se que a maioria dos entrevistados (17 deles) comunga desse valor, tanto de modo pessoal como profissional, além de perceber a possibilidade de construir relações de amizade no trabalho (8 deles) diante de uma quantidade elevada e diversificada de pessoas (6 deles), como observado por Freire (2009).

Por outro lado, 5 entrevistados acreditam que nem sempre é possível relacionar-se ( 2 deles) e nem desenvolver conversas durante o horário de trabalho (2 deles). Esses dados também indicam que os operadores se deparam com um paradoxo laboral entre qualidade e quantidade de atendimentos, ou seja, de um lado são cobrados para fornecer aos clientes um serviço de alta qualidade e de outro devem aumentiar ao máximo sua produtividade, como demonstram os seguintes relatos:

[...] às vezes, eu quero brincar, conversar, fazer alguma coisa com meu colega que está do lado, só que eu sou banida por isso, eu tenho que prestar 100\% de atenção no meu atendimento, mesmo que eu peça um momento de poucos minutos, mas eu não posso [...]. (E13)

Com certeza, nosso café da manhã especial [realizado diariamente antes do início do expediente], muita gente se junta à gente, aí, temos a oportunidade de conhecer muita gente, fazer amizade, levar essa amizade para fora da empresa, o que eu acho mais legal, então, com certeza! (E12)

Detalhando o valor "prestígio", o de menor predomínio na percepção dos respondentes e dos entrevistados, de modo geral, ressalte-se que 16 dos entrevistados afirmam sentir que as pessoas valorizam o trabalho realizado por eles. Reconhecem que adquirem conhecimento capaz de ajudar terceiros também externos ao âmbito organizacional (4 deles), além de trabaIhar para a empresa contratante (4 deles). Entretanto, 9 entrevistados não identificam esse valor em seu trabalho, devido à sensação de que os demais não o valorizam (5 deles), que se trata de uma atuação marginalizada pela sociedade (1 deles), considerada atuação de "doidos" (1 deles), a qual aguça nos indivíduos o sentimento de exploração (1 deles).

Eu acho que sim, como eu te falei a gente adquire alguns conhecimentos [...] a gente acaba que leva um pouco de prestígio porque a gente pode explicar algo às pessoas fora da empresa. (E14)

No entanto, os mecanismos de defesa e de resistência desenvolvidos, como "enrolar" o cliente ou se aproveitar de informações disponibilizadas ao call center pela empresa contratante, portanto, privilegiadas, na esfera particular denotam um nível de prestígio menor que o verbalizado pelos entrevistados, além de concretizar atos de incivilidade, como mencionado por Pearson e Porath (2005).

Depende! Quando eu falo que eu trabalho na [call center] pra alguém que trabalha na [nome de outro call center] e na [nome de outro call center], eles falam: "Poxa, você trabalha no céu!". Eles só olham o lado do salário. Mas eles não olham o lado que é a exploração. Porque imagina: na [nome de outro call center] você vai atender no máximo 50 ligações. E eu, por dia, no mínimo [tom enfático], 150, e quando eu enrolo o cliente! Quando eu estou dentro da média de atendimento, eu atendo a 250, 300 ligações, por dia! Já cheguei em um mês a atender 7 mil pessoas. (E07) 
Essas possíveis conexões entre os valores foram alvo do terceiro objetivo específico traçado para este estudo, ou seja, identificar possíveis correlações entre os valores abordados. Para tanto, foram realizados testes de correlação de Spearman, considerando os valores organizacionais entre si, os valores do trabalho entre si e os valores organizacionais e os valores do trabaIho. Dos 66 testes realizados, apenas 2 não resultaram em correlações significativas, ambos relacionados ao valor do trabalho "estabilidade", que não apresentou resultados significativos (valor $p$ abaixo de 0,05 ) quando analisado junto com os valores organizacionais "bem-estar" (valor p 0,686) e "tradição" (valor $p$ 0,093), destacados em negrito, como se observa na Tabela 3.

Tabela 3

\section{Resultados dos testes de correlação entre os valores organizacionais e os valores do trabalho}

\begin{tabular}{|c|c|c|c|c|c|c|c|c|c|c|c|c|}
\hline \multicolumn{2}{|c|}{ Valores } & \multicolumn{8}{|c|}{ Organizacionais } & \multicolumn{3}{|c|}{ Trabalho } \\
\hline & & Aut & $\mathrm{BE}$ & Real O & Dom & Prest $\mathrm{O}$ & Conf & Trad & PC & Real T & RS & Prest T \\
\hline \multirow{7}{*}{$\begin{array}{l}\frac{n}{\pi} \\
\frac{n}{0} \\
\frac{0}{U} \\
\mathbb{N} \\
\frac{N}{5} \\
\mathbb{0} \\
0 \\
0\end{array}$} & $\mathrm{BE}$ & $\begin{array}{c}0,815 \\
(0,000)\end{array}$ & & & & & & & & & & \\
\hline & Real O & $\begin{array}{c}0,836 \\
(0,000)\end{array}$ & $\begin{array}{c}0,675 \\
(0,000)\end{array}$ & & & & & & & & & \\
\hline & Dom & $\begin{array}{c}0,599 \\
(0,000)\end{array}$ & $\begin{array}{c}0,468 \\
(0,000)\end{array}$ & $\begin{array}{c}0,525 \\
(0,000)\end{array}$ & & & & & & & & \\
\hline & Prest $\mathrm{O}$ & $\begin{array}{c}0,740 \\
(0,000)\end{array}$ & $\begin{array}{c}0,616 \\
(0,000)\end{array}$ & $\begin{array}{c}0,707 \\
(0,000)\end{array}$ & $\begin{array}{c}0,630 \\
(0,000)\end{array}$ & & & & & & & \\
\hline & Conf & $\begin{array}{c}0,656 \\
(0,000)\end{array}$ & $\begin{array}{c}0,482 \\
(0,000)\end{array}$ & $\begin{array}{c}0,731 \\
(0,000)\end{array}$ & $\begin{array}{c}0,650 \\
(0,000)\end{array}$ & $\begin{array}{c}0,675 \\
(0,000)\end{array}$ & & & & & & \\
\hline & Trad & $\begin{array}{c}0,509 \\
(0,000)\end{array}$ & $\begin{array}{c}0,484 \\
(0,000)\end{array}$ & $\begin{array}{c}0,453 \\
(0,000) \\
\end{array}$ & $\begin{array}{c}0,521 \\
(0,000)\end{array}$ & $\begin{array}{c}0,520 \\
(0,000)\end{array}$ & $\begin{array}{c}0,473 \\
(0,000) \\
\end{array}$ & & & & & \\
\hline & PC & $\begin{array}{c}0,848 \\
(0,000)\end{array}$ & $\begin{array}{c}0,752 \\
(0,000)\end{array}$ & $\begin{array}{c}0,835 \\
(0,000)\end{array}$ & $\begin{array}{c}0,536 \\
(0,000)\end{array}$ & $\begin{array}{c}0,694 \\
(0,000)\end{array}$ & $\begin{array}{c}0,706 \\
(0,000)\end{array}$ & $\begin{array}{c}0,509 \\
(0,000)\end{array}$ & & & & \\
\hline \multirow{5}{*}{ 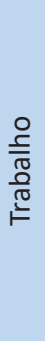 } & Real T & $\begin{array}{c}0,244 \\
(0,000)\end{array}$ & $\begin{array}{c}0,145 \\
(0,004)\end{array}$ & $\begin{array}{c}0,216 \\
(0,000)\end{array}$ & $\begin{array}{c}0,205 \\
(0,000)\end{array}$ & $\begin{array}{c}0,218 \\
(0,000)\end{array}$ & $\begin{array}{c}0,265 \\
(0,000)\end{array}$ & $\begin{array}{c}0,142 \\
(0,005)\end{array}$ & $\begin{array}{c}0,213 \\
(0,000)\end{array}$ & & & \\
\hline & RS & $\begin{array}{c}0,343 \\
(0,000)\end{array}$ & $\begin{array}{c}0,256 \\
(0,000) \\
\end{array}$ & $\begin{array}{c}0,316 \\
(0,000) \\
\end{array}$ & $\begin{array}{c}0,264 \\
(0,000) \\
\end{array}$ & $\begin{array}{c}0,309 \\
(0,000)\end{array}$ & $\begin{array}{c}0,302 \\
(0,000) \\
\end{array}$ & $\begin{array}{c}0,215 \\
(0,000) \\
\end{array}$ & $\begin{array}{c}0,325 \\
(0,000)\end{array}$ & $\begin{array}{c}0,741 \\
(0,000) \\
\end{array}$ & & \\
\hline & Prest T & $\begin{array}{c}0,286 \\
(0,000)\end{array}$ & $\begin{array}{c}0,281 \\
(0,000)\end{array}$ & $\begin{array}{c}0,204 \\
(0,000)\end{array}$ & $\begin{array}{c}0,213 \\
(0,000)\end{array}$ & $\begin{array}{c}0,222 \\
(0,000)\end{array}$ & $\begin{array}{c}0,166 \\
(0,001)\end{array}$ & $\begin{array}{c}0,289 \\
(0,000)\end{array}$ & $\begin{array}{c}0,218 \\
(0,000)\end{array}$ & $\begin{array}{c}0,513 \\
(0,000)\end{array}$ & $\begin{array}{c}0,532 \\
(0,000)\end{array}$ & \\
\hline & Fst & 0,107 & 0,021 & 0,159 & 0,165 & 0,184 & 0,276 & 0,085 & 0,126 & 0,546 & 0,436 & 0,357 \\
\hline & LSt & $(0,034)$ & $(0,686)$ & $(0,002)$ & $(0,001)$ & $(0,000)$ & $(0,000)$ & $(0,093)$ & $(0,013)$ & $(0,000)$ & $(0,000)$ & $(0,000)$ \\
\hline
\end{tabular}

Fonte: Elaborada pelas autoras.

Nota: (1) Valores organizacionais: Aut - Autonomia; BE - Bem-estar; Real O - Realização; Dom - Domínio; Prest O -Prestígio; Conf Conformidade; Trad - Tradição; PC - Preocupação com a coletividade; (2) Valores do trabalho: Real T - Realização; RS - Relações sociais; Prest T - Prestígio; Est - Estabilidade.

Os resultados do valor organizacional "estabilidade" podem ser compreendidos à luz da instabilidade das relações de trabalho mencionada por Paiva, Dutra e Luz $(2013 ; 2015)$ e Cappelli e Keller (2013), da frágil proteção jurídica relatada por Mendes, Vieira e Morrone (2009), somadas às características do trabalho dos operadores - rotineiro, repetitivo, ininterrupto - e, daí, aos processos de adoecimento físico e mental (ANTUNES, 2009; 2010; 2012), que certamente minam o compartilhamento da crença de que a organização se preocupa com seu "bem-estar". Quanto à ausência de correlação entre "estabilidade" e "tradição", a literatura não aponta possibilidades de inferências a esse respeito, concretizando-se como um aspecto a ser aprofundado em investigações futuras.

Note-se que uma das poucas relações entre valores organizacionais e valores do trabalho externalizada por parte dos entrevistados relaciona-se ao prestígio no âmbito organizacional e ao prestígio no escopo do trabalho. Alguns operadores (6 
deles) não percebem "prestígio" no âmbito organizacional, porque a profissão de operador não é bem vista por terceiros e outros (4 deles) afirmaram que o prestígio que poderiam ter seria apenas em prol da atuação para a empresa contratante do call center. Tais posições referem-se, de fato, ao valor do trabalho "prestígio", ou seja, relacionado ao que efetivamente o trabalhador faz. Esse reconhecimento da empresa não é desconectado, por parte dos operadores, do processo desgastante de trabalho, o que aparenta colocar em "xeque" tal prestígio observado, o que foi verbalizado em diversos relatos, como este:

Quando eu falo que eu trabalho lá, o povo acha que eu estou no céu... Ahh... De certa forma é um prestígio mal visto. Eles não sabem o que eu passo diariamente, o que eu estou fazendo para eles me mandarem embora, mas eles não me mandam. Outros call centers falam: "Nossa, quanto que você ganha?" Aí eu falo: "Mil e quarenta e um..."; "Nossa! Menina... Como você ganha bem!". Entendeu? Por causa da diferença salarial. Mas, eles não perguntam assim: "Aqui, quanto que você atende por dia?" Aham... Porque na hora que eu vou falar assim: "Não, é 300 ligações, bonito!". Aí, vão falar assim: "Não, muito obrigada! Eu fico aqui com as minhas 50!". Entendeu? É... Eles não veem os dois lados da moeda. Porque, imagina, gente, quando eu falo 300 ligações, o povo acha que é pouco. Mas, num call center, você sai louco. De não conseguir contar uma moeda. Você não consegue contar... É muita loucura! (E07)

Assim, tais relatos ratificam o resultado do teste, que apontou uma correlação positiva entre Prestígio organizacional (Prest O) e Prestígio no trabalho (Prest T), com rho 0,222 e valor $p$ 0,000. Os relatos indicam que tais tipos de prestígio apresentam comportamento semelhante ao observado nas respostas dos questionários, ou seja, quando um é elevado, o outro segue a mesma tendência, sendo a recíproca verdadeira.

Além dessa, outra relação observada pelos entrevistados se deu entre o valor organizacional "preocupação com a coletividade" e o valor do trabalho "relações sociais", que ratificam a correlação direta (rho 0,325) e significativa (valor $p 0,000)$ foi percebido por 16 dos entrevistados como importante, salientando-se sua relação com o cumprimento de metas coletivas ( 7 deles), as premiações por equipe (4 deles) e o resultado ( 2 deles). Considerando que 3 deles manifestaram-se de modo ambíguo (E02, E08, E13), 9 dos entrevistados não percebem tal preocupação no cotidiano da empresa e outros 4 relataram a diferenciação existente entre o tratamento concedido aos que trabalham em áreas diferentes do call center (ativo e receptivo). Os seguintes relatos refletem tais posições:

[...] a gente trabalha em equipe, então, eu acho que sim... então, se um erra, todos pagam por aquilo ali. (E02)

Não, [o call center] não se preocupa. Por exemplo, você tem lá a sua equipe e essa equipe faz um trabaIho bom, ela cumpre as metas direitinho, mas eles sempre, em um período, têm que desfazer a equipe. Então, ao invés deles trabalharem com a produtividade, não, eles gostam de mexer muito até onde já está muito bom. Eles gostam de mudanças [...]. Um dia está na equipe de um, um dia você está na equipe de outra [...]. (E22)

Outros relatos também refletem o empenho da organização para promover ganhos de produtividade, atuando de maneira flexível e ágil (SENNETT, 2007), às custas do enfraquecimento dos laços sociais e de relações de trabalho instáveis e temporárias (PAIVA, DUTRA e LUZ, 2013; 2015; CAPPELLI e KELLER, 2013), levando a dificuldades para estabelecer uma colaboração efetiva e enfraquecendo as relações de confiança entre as pessoas (SENNETT, 2007), o que fomenta, desse modo, relações sociais superficiais no interior da organização, o que pode ser observado na análise do valor do trabalho "relações sociais" e da correlação identificada entre eles.

Em síntese, não se percebeu plena homogeneidade entre os dados obtidos por meio das entrevistas e dos questionários, já que os valores do trabalho "prestígio" e "relações sociais" apresentaram resultados mais positivos nas entrevistas que nos questionários, e o inverso ocorreu com os dois outros, ou seja, os valores "realização" e "estabilidade" foram mais bem avaliados pelos respondentes dos questionários que pelos entrevistados.

De posse desses resultados, traçamos as considerações finais. 


\section{CONSIDERAÇÕES FINAIS}

Diante dos dados coletados junto a operadores do call center em análise, percebeu-se que o valor organizacional mais comungado foi "conformidade", tanto na parte quantitativa como qualitativa da pesquisa. Como se trata de um call center, prezar pelo respeito às regras, às posturas e aos modelos de comportamentos predefinidos mostra-se algo compreensível mediante a natureza do trabalho executado pela maioria (operadores de telemarketing), permeado por cobranças e metas.

Quanto aos valores do trabalho, a "realização no trabalho" se destacou dos demais, mesmo se considerando que "estabilidade" obteve resultados mais elevados na parte quantitativa da pesquisa, o que não foi tão corroborado na parte qualitativa. Note-se que a valorização do conhecimento adquirido, a interação com clientes e o sentimento de vínculo, mesmo que indireto, com uma grande empresa (a contratante dos serviços do call center), capaz de estimular prazer e realização, tanto pessoal como profissional, foram aspectos mais verbalizados que a estabilidade no emprego.

Os testes estatísticos de correlação apontaram correlações significativas diretas entre os valores organizacionais e os valores do trabalho analisados, à exceção do valor do trabalho "estabilidade" quando analisado junto com os valores organizacionais "bem-estar" e "tradição": para o primeiro, a literatura possibilitou inferências, o que não ocorre entre "estabilidade" e "tradição", fato que fomenta a realização de outras pesquisas. Além disso, os entrevistados verbalizaram conexões diretas entre os valores "prestígio" no âmbito organizacional e no do trabalho, assim como entre o valor organizacional "preocupação com a coletividade" e o valor do trabalho "relações sociais"; em ambos os casos, características do tipo de organização abordada e o próprio trabalho típico de operadores de call center foram considerados para identificar possíveis razões.

Assim, a triangulação de métodos empregada nesta pesquisa contribuiu significativamente para a compreensão do fenômeno em foco, em especial nos aspectos em que os dados não guardavam similaridade, indicando a necessidade de replicação (em outras empresas similares) e aprofundamento (por meio de aportes metodológicos mais robustos) em futuras pesquisas.

Para a área de estudos do comportamento humano em organizações, este estudo se apresenta como precursor no sentido de reunir dois construtos - valores organizacionais e valores do trabalho - que vêm sendo estudados separadamente ou reunidos a outras temáticas do campo do comportamento humano nas organizações, apesar dos modelos de pesquisa desenvolvidos no Brasil terem origem semelhante aos tipos motivacionais de Shalom H. Schwartz. Além disso, estudar tais temáticas no contexto selecionado, uma empresa de call center que presta serviço para uma grande organização pública, contribuiu para a compreensão de particularidades do cotidiano do trabalho de operadores que sinalizam necessidades de diferenciadas políticas e práticas de gestão de pessoas, devido aos dilemas, às dificuldades e aos mecanismos de defesa e resistência observados. Vale frisar duas limitações identificadas no estudo: a análise de apenas um call center e de profissionais que ocupam um mesmo cargo (operadores de telemarketing).

Diante dos achados, das contribuições e das limitações deste estudo, considera-se importante dar continuidade à pesquisa, incorporando algumas características, como: ampliar a coleta para outros call centers, perpassando cargos diferenciados, visando a identificar similaridades e diferenças, o que poderá contribuir para o avanço das pesquisas em tal espaço laboral, assim como para as práticas de gestão de pessoas; aprofundar as questões relacionadas a valores, em outros níveis, como pessoal e profissional, dadas as conexões observadas na parte qualitativa desta pesquisa; realizar estudos multitemáticos, considerando outras conexões apresentadas pelos entrevistados com estresse ocupacional, qualidade de vida no trabalho, burnout, prazer e sofrimento no trabalho, justiça e atitudes retaliatórias, vínculos organizacionais, dentre outros, o que pode promover o desenvolvimento de modelos conceituais mais robustos, principalmente contando com a possibilidade de manter as triangulações metodológicas; isso também possibilitaria um refinamento estatístico, trabalhando com outros testes bivariados, assim como estatística multivariada e análises de regressão, o que contribuiria para a construção de modelos teóricos mais robustos no campo do comportamento humano nas organizações. 


\section{REFERÊNCIAS}

ANDRADE, D. L. Valores organizacionais e do trabalho: um estudo com agentes prisionais e agentes socioeducativos em Belo Horizonte. 127f. Dissertação (Mestrado em Administração) - Faculdade Novos Horizontes, Belo Horizonte, 2011.

ANTUNES, R. Século XXI: nova era da precarização estrutural do trabalho. In: ANTUNES, R.; Braga, R. (Org.). Infoproletários. São Paulo: Boitempo, 2009. 231-238 p.

ANTUNES, R. Adeus ao trabalho? São Paulo: Cortez, 2010.

ANTUNES, R. A nova morfologia do trabalho no Brasil. Reestruturação e precariedade. Revista Nueva Sociedad, n. 232, p. 3-4, 2012.

AZEVEDO, C. E. F. et al. Estratégia de triangulação: objetivos, possibilidades, limitações e proximidades com o pragmatismo. In: ENCONTRO DE GESTÃO DE PESSOAS E RELAÇÕES DE TRABALHO, 4.; 2013. Brasília. Anais... Brasília, DF: ANPAD, 2013.

BARDIN, L. Análise de conteúdo. Lisboa: Ed. 70, 2009.

BERGER, P. L.; LUCKMANN, T. A construção social da realidade. Petrópolis, RJ: Vozes, 2004.

BESHAROV, M. L. The relational ecology of identification: how organizational identification emerges when individuals hold divergent values. Academy of Management Journal, v. 57, n. 5, p. 1485-1512, 2014.

BORGES, L. O. Valores de trabalhadores de baixa renda. In: TAMAYO, A.; PORTO, J. B. (Org.). Valores e comportamento nas organizações. Petrópolis, RJ: Vozes, 2005. 233-250 p.

BORLIDO, F. C. Valores organizacionais e do trabalho na percepção de jovens recém-inseridos no mercado de trabalho: o caso dos alunos do Espro. 147f. Dissertação (Mestrado em Administração) Faculdade Novos Horizontes, Belo Horizonte, 2011.

CAPPELLI, P.; KELLER, J. R. Classifying work in the new economy. Academy of Management Review, v. 38, n. 4, p. 575-596, 2013.

COLLIS, J.; HUSSEY, R. Pesquisa em administração. Porto Alegre: Bookman, 2005.

COSTA, A. C. R.; CARNEIRO, C. Inter-relações entre valores organizacionais e valores individuais. In: BRITO, L. M. O. (Org.). Práticas em pesquisas em gestão de pessoas. Fortaleza: Ed. UFC, 2008. 354-361 p.

COSTA, M. G. D. Em busca de um modelo brasileiro de mentoria e liderança: o caso de uma organização de call center. $335 \mathrm{f}$. Dissertação (Mestrado em Gestão Empresarial) - Faculdade Boa Viagem, Recife, 2007.

FERREIRA, M. C.; FERNANDES, H. A.; SILVA, A. P. C. Valores organizacionais: um balanço da produção nacional do período de 2000 a 2008 nas áreas de administração e psicologia. Revista de Administração Mackenzie, v. 10, n. 3, p. 84-100, 2009.

FREIRE, K. Call center: o primeiro grande emprego. São Paulo: Scortecci, 2009.

GEHMAN, J.; TREVIÑO, L. K.; GARUD, R. Values work: a process study of the emergence and performance of organizational values practices. Academy of Management Journal, v. 56, n. 1, p. 84-112, 2013.
GIL, A. C. Como elaborar projetos de pesquisa. São Paulo: Atlas, 2009.

GOUVEIA, V. V. et al. Teoria funcionalista dos valores humanos: aplicações para as organizações. Revista de Administração Mackenzie, v. 10, n. 3, p. 34-59, 2009.

HAUFF, S.; KIRCHNER, S. Identifying work value patterns: cross-national comparison and historical dynamics. International Journal of Manpower, v. 36, n. 2, p. 151-168, 2015.

HEWLIN, P. F. And the award for best actor goes to...: facades of conformity in organizational settings. Academy of Management Review, v. 28, n. 4, p. 633-642, 2003.

HOCH, E. E.; ANDRADE, T.; FOSSÁ, M. I. T. Valores relativos ao trabalho e gênero: a visão dos gerentes de uma organização bancária. In: ENCONTRO DA ANPAD, 33. 2009, São Paulo. Anais... Rio de Janeiro: ANPAD, 2009.

JICK, T. D. Mixing qualitative and quantitative methods: triangulation in action. Administrative Science Quartely, v. 24, n. 4, p. 602-611, 1979.

LANCMAN, S.; SZNELWAR, L. I. Christophe Dejours: da psicopatologia à psicodinâmica do trabalho. Rio de Janeiro/Brasília, DF: Fiocruz/ Paralelo 15, 2004.

LASPISA, D. F. A influência do conhecimento individual na memória organizacional: estudo de caso em um call center. 120f. Dissertação (Mestrado em Engenharia e Gestão do Conhecimento) - Programa de Pós-Graduação em Engenharia e Gestão do Conhecimento, Universidade Federal de Santa Catarina, Florianópolis, 2007.

LIANG, Y. W. The relationships among work values, burnout, and organizational citizenship behaviors. International Journal of Contemporary Hospitality Management, v. 24, n. 2, p. 251-268, 2012.

MAIA, L. F. R. B.; OLIVEIRA, J. D. O. Valores Organizacionais e seu Impacto sobre o Clima e a Satisfação no Trabalho: Percepção dos Técnico-Administistrativos de uma Instituição Federal de Ensino Superior. In: ENCONTRO DE GESTÃO DE PESSOAS E RELAÇÕES DE TRABALHO, 1.; 2007. Natal. Anais... Natal, RN: ANPAD, 2007.

MAIA, L. F. R. B.; OLIVEIRA, J. D.; XIMENES, V. M. Valores e comportamento de cidadania organizacional: um estudo no contexto de um hospital universitário. In: BRITO, L. M. P. (Org.). Práticas de pesquisas em gestão de pessoas. Fortaleza: Imprensa Universitária, 2007. 43-66 p.

MATOZO, L. Call center: modismo ou realidade? Rio de Janeiro: Record, 2000.

MELO, M. C. O. L. et al. Em busca de técnicas complementares em pesquisa qualitativa no campo da administração. In: ENCONTRO DE GESTÃO DE PESSOAS E RELAÇÕES DE TRABALHO, 1.; 2007, Recife. Anais... Recife: ANPAD, 2007.

MENDES, A. M. B.; VIEIRA, A. P.; MORRONE, C. F. Prazer, sofrimento e saúde mental no trabalho de teleatendimento. Revista Eletrônica de Ciência Administrativa, v. 8, n. 2, p. 151-158, 2009.

MOURÃO, L. et al. Valores, suporte psicossocial e impacto do treinamento no trabalho. In: ENCONTRO DA ANPAD, 33. 2003, Atibaia. Anais... Rio de Janeiro: ANPAD, 2003. 
NOGUEIRA, C. M. O trabalho duplicado. São Paulo: Expressão Popular, 2012.

OLIVEIRA, A.; TAMAYO, A. Inventário de perfis de valores organizacionais. Revista de Administração, v. 39, n. 2, p. 129-140, 2004.

PAIVA, K. C. M. Valores organizacionais e do trabalho: um estudo com jovens trabalhadores. In: ENCONTRO DA ANPAD, 36. 2012, Rio de Janeiro. Anais... Rio de Janeiro: ANPAD, 2012.

PAIVA, K. C. M. Valores organizacionais e do trabalho: um estudo com jovens trabalhadores brasileiros. Tourism \& Management Studies, v. 9, n. 2, p. 100-106, 2013.

PAIVA, K. C. M.; DUTRA, M. R. S.; LUZ, T. R. Comprometimento organizacional: um estudo com trabalhadores de um call center. In: ENCONTRO DE GESTÃO DE PESSOAS E RELAÇÕES DE TRABALHO, 4. 2013, Brasília. Anais... Brasília, DF: ANPAD, 2013.

PAIVA, K. C. M.; DUTRA, M. R. S.; LUZ, T. R. Comprometimento organizacional de trabalhadores de call center. Revista de Administração da USP, v. 50, n. 3, p. 310-324, 2015.

PARKER, S. K. et al. Making the most of structural support: moderating influence of employees' clarity and negative affect. Academy of Management Journal, v. 56, n. 3, p. 867-892, 2013.

PEARSON, C. M.; PORATH, C. L. On the nature, consequences and remedies of workplace incivility: No time for "nice"? Think again. Academy of Management Executive, v. 19, n. 1, p. 7-18, 2005.

PEREZ, L. F. Apontamentos sobre juventude, religião e valores. In: PEREZ, L. F.; TAVARES, F.; CAMURÇA, M. Ser jovem em Minas Gerais. Belo Horizonte: Argvmentvm, 2009. 99-123 p.

PORTO, J. B.; TAMAYO, A. Escala de valores relativos ao trabalho: EVT. Psicologia: Teoria e Pesquisa, v. 19, n. 2, p. 145-152, 2003.

PORTO, J. B.; TAMAYO, A. Valores do trabalho. In: SIQUEIRA M. M. M. (Org.). Medidas do comportamento organizacional. Porto Alegre: Artmed, 2008. 295-307 p.

PORTO, J. B. et al. Análise fatorial confirmatória da escala de valores relativos ao trabalho. In: ENCONTRO DA ANPAD, 30. 2006, Salvador. Anais... Salvador: ANPAD, 2006.

RALSTON, D. A. et al. The impact of national culture and economic ideology on managerial work values: a study of the United States, Russia, Japan, and China. Journal of International Business Studies, v. 28, n. 1 , p. 177-207, 1997

ROKEACH, M. The nature of human values. New York: Free Press, 1973.

ROKEACH, M. Crenças, atitudes e valores. Rio de Janeiro: Interciência, 1981.

ROS, M. Psicologia social dos valores: uma perspectiva histórica. In: ROS, M.; GOUVEIA, V. V. (Org.). Psicologia social dos valores humanos. São Paulo: Senac, 2006. 23-53 p.

ROS, M.; SCHWARTZ, S. H.; SURKISS, S. Basic individual values, work values, and the meaning of work. Applied Psychology: An International Review, v. 48, p. 49-71, 1999.

SCHWARTZ, S. H. Universals in the content and structure of values: theoretical advances and empirical tests in 20 countries. In: ZANNA,
M. (Org.). Advances in experimental social psychology. Orlando, FL: Academic Press, 1992. v. 25, 1-65 p.

SCHWARTZ, S. H. A theory of cultural values and some implications for work. Applied Psychology: An International Review, v. 48, p. 23-47, 1999.

SCHWARTZ, S. H. Valores humanos básicos: seu contexto e estrutura intercultural. In: TAMAYO, A.; PORTO, J. B. (Org.). Valores e comportamento nas organizações. Petrópolis, RJ: Vozes, 2005. 21-55 p.

SENNETT, R. A corrosão do caráter. Rio de Janeiro: Record, 2007.

SILVA, A. B. A fenomenologia como método de pesquisa em estudos organizacionais. In: SILVA, A. B.; GODOI, C. K.; BANDEIRA-DEMELLO, R. (Org.). Pesquisa qualitativa em estudos organizacionais. São Paulo: Saraiva, 2006. 267-297 p.

SILVA, J. R. G. et al., Operadores de call center: inconsistências e desafios da gestão de pessoas. In: ENCONTRO DA ANPAD, 26. 2002 , Rio de Janeiro. Anais... Rio de Janeiro: ANPAD, 2002.

SILVA, M. F.; BORINI, F. M.; TREVISAN, L. N. Práticas organizacionais dos call centers. In: ENCONTRO DA ANPAD, 31. 2007, Rio de Janeiro. Anais... Rio de Janeiro: ANPAD, 2007.

TAMAYO, A. Impacto dos valores pessoais e organizacionais sobre o comportamento organizacional. In: TAMAYO, A.; PORTO, J. B. Valores e comportamento nas organizações. Petrópolis, RJ: Vozes, 2005. $160-186 p$.

TAMAYO, A. Valores organizacionais. In: SIQUEIRA M. M. M. (Org.). Medidas do comportamento organizacional. Porto Alegre: Artmed, 2008. 309-340 p.

TAMAYO, A.; BORGES, L. O. Valores do trabalho e das organizações. In: ROS, M.; GOUVEIA, V. V. (Org.). Psicologia social dos valores humanos. São Paulo: Senac, 2006. 397-431 p.

TAMAYO, A.; GONDIM, M. G. C. Escala de valores organizacionais. Revista de Administração, v. 31, n. 2, p. 62-72, 1996.

TAMAYO, A.; MENDES, A. M.; PAZ, M. G. T. Inventário de valores organizacionais. Estudos de Psicologia, v. 5, n. 2, p. 289-315, 2000.

TEIXEIRA, J. C.; NASCIMENTO, M. C. R.; ANTONIALLI, L. M. Perfil de estudos em administração que utilizaram triangulação metodológica: uma análise dos anais do EnANPAD de 2007 a 2011. Revista de Administração, v. 48, n. 4, p. 800-812, 2013.

TEIXEIRA, M. L. M. Valores humanos \& gestão. São Paulo: Senac, 2008. VASCONCELLOS, L. H. R.; MARX, R.; FIGUEIREDO, J. C. B. A contribuição do call center para a inovação em empresas de serviço no Brasil. In: ENCONTRO DA ANPAD, 35. 2011, Rio de Janeiro. Anais... Rio de Janeiro: ANPAD, 2011.

VERGARA, S. C. Projetos e relatórios de pesquisa em administração. São Paulo: Atlas, 2009.

VIEIRA, P. R.; CARDOSO, A. S. R. Construção, desconstrução e reconstrução de sistemas de valores nas organizações. Cad. EBAPE.BR, v. 1, n. 2, p. 1-11, 2003. 


\section{Kely César Martins de Paiva}

Doutora em Administração pela Universidade Federal de Minas Gerais (UFMG); Professora e Pesquisadora do Centro de Pós-graduação e Pesquisa em Administração do Departamento de Ciências Administrativas da Faculdade de Ciências Econômicas da Universidade Federal de Minas Gerais (CEPEAD/ CAD/FACE/UFMG).E-mail: kelypaiva@face.ufmg.br

\section{Michelle Regina Santana Dutra}

Mestre em Administração pela Faculdade Novos Horizontes (FNH); Professora, Analista de Processos e Pesquisadora do Instituto de Ciências Sociais Aplicadas do Centro Universitário de Belo Horizonte (ICSA/UNIBH).E-mail: michelle.dutra@prof.unibh.br 